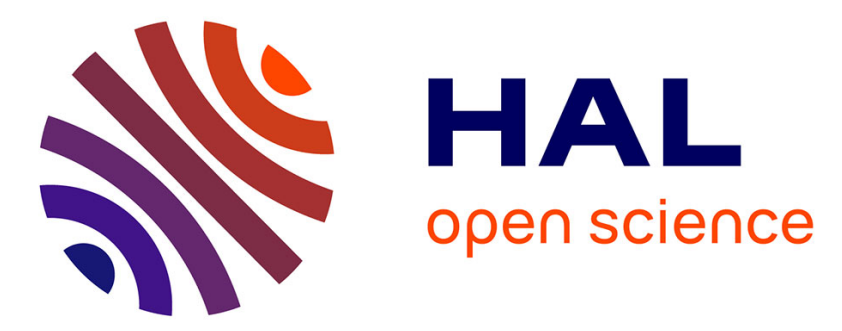

\title{
Determination of the permeability of seepage flow paths in dams from self-potential measurements
}

\author{
A. Soueid Ahmed, A. Revil, A. Boleve, B. Steck, C. Vergniault, J.R. \\ Courivaud, Damien Jougnot, Micheline Abbas
}

\section{- To cite this version:}

A. Soueid Ahmed, A. Revil, A. Boleve, B. Steck, C. Vergniault, et al.. Determination of the permeability of seepage flow paths in dams from self-potential measurements. Engineering Geology, 2020, 268, pp.105514. 10.1016/j.enggeo.2020.105514 . hal-02510841

\section{HAL Id: hal-02510841 \\ https://hal.sorbonne-universite.fr/hal-02510841}

Submitted on 4 Nov 2020

HAL is a multi-disciplinary open access archive for the deposit and dissemination of scientific research documents, whether they are published or not. The documents may come from teaching and research institutions in France or abroad, or from public or private research centers.
L'archive ouverte pluridisciplinaire HAL, est destinée au dépôt et à la diffusion de documents scientifiques de niveau recherche, publiés ou non, émanant des établissements d'enseignement et de recherche français ou étrangers, des laboratoires publics ou privés. 


\section{Determination of the permeability of seepage flow}

2 paths in dams from self-potential measurements

3

4 A. Soueid Ahmed ${ }^{1}$, A. Revil ${ }^{1}$, A. Bolève ${ }^{2}$, B. Steck ${ }^{3}$, C. Vergniault ${ }^{4}$,

$5 \quad$ J.R. Courivaud ${ }^{5}$, D. Jougnot ${ }^{6}$, and M. Abbas ${ }^{7}$

6 (1) Univ. Grenoble Alpes, Univ. Savoie Mont Blanc, CNRS, IRD, IFSTTAR, ISTerre, 38000 Grenoble, France

7 (2) FUGRO France, 34 Allée du Lac d'Aiguebelette, 73375 Le Bourget-du-Lac Cedex, France

8 (3) EDF R\&D, 6 quai Watier, 78400 Chatou, France

9 (4) EDF DI-TEGG, 905 avenue du Camp de Menthe, 13097 Aix-en-Provence, France

10 (5) Université de Rouen, M2C, UMR 6143, CNRS, Morphodynamique Continentale et Côtière, Mont Saint Aignan, France

11 (6) Sorbonne Université, CNRS, EPHE, UMR 7619 Metis, 4 place Jussieu, 75005 Paris, France

12 (7) The International University of Beirut (BIU), School of Engineering, Beirut, Lebanon

13

14

15

16

17

18

19

20

21

22

23

24

Short title: Permeability in dams

Corresponding author: Abdellahi Soueid Ahmed (abdellahi.soueid-ahmed@univ-smb.fr)

Emails: abdellahi.soueid-ahmed@univ-smb.fr; andre.revil@univ-smb.fr;

a.boleve@fugro.com; christophe.vergniault@edf.fr; barthelemy.steck@edf.fr;

damien.jougnot@upmc.fr; jean-robert.courivaud@edf.fr; mohamad.abbas01@liu.edu.lb 
27 Abstract. The flow of the pore water in porous media generates an electrical current known as the streaming current. This current is due to the drag of the excess of charge contained in the electrical diffuse layer coating the surface of the grains. This current is associated with an electric field called the streaming potential field. The fluctuations of this field can be remotely measured using a set of non-polarizable electrodes located at the ground surface or in wells and a sensitive voltmeter. The self-potential method (SP) aims at passively measuring the streaming potential anomalies associated with ground water flow. We present a stochastic numerical framework for inverting self-potential data in order to localize seepages in dams and characterize their permeability and Darcy velocity. Our approach is based on the use of Markov chains Monte Carlo (McMC) method for solving the inverse problem. We performed first a validation of the method on a synthetic case study and then on large-scale field surveys on three different dams. Our approach is successful in localizing seepages and determining their permeability. A sensitivity study is performed on each of these three dams to better define the hydraulic and electrical parameters influencing the self-potential signal and the uncertainties associated with the estimation of those parameters. Our results show that the self-potential method can provide quantitative hydrogeological information for the characterization of seepages in dams and dikes.

Keywords: Self-potential, forward modeling, inverse modeling, earth dam, seepage characterization. 


\section{Introduction}

Earth dams play a vital and indispensable role in our modern societies. They can be designed to store large volumes of water for domestic and industrial purposes such as supplying hydroelectric power stations. The flow of the water through a dam can lead to internal erosion of its inner structure, which may trigger in turn suffusion and subsidence phenomena (e.g., Bonelli, 2013; Ferdos et al., 2018; Howard and McLane, 1988; James, 1968). These phenomena can give rise to dramatic and irreversible consequences leading to the potential collapse or failure of the dams (e.g., Gutiérrez et al., 2003). Consequently; we need to develop reliable, efficient, and economically viable remote techniques to monitor dams.

Geophysical techniques can be used to non-intrusively probe dams and detect the occurrence of anomalous seepages within their structure. Ground-Penetrating Radar (e.g., Antoine et al., 2015; Di Prinzio et al., 2010; Hui and Haitao, 2011; Li et al., 2018; Xu et al., 2010) is among these techniques. However, GPR suffers from a major limitation, which is its small depth of investigation in conductive materials because of the damping of electromagnetic waves in these conditions. An alternative to GPR is the use of galvanometric geoelectrical methods (i.e., self-potential, resistivity, and induced polarization methods). The Electrical Resistivity Tomography (ERT) method is valuable for imaging the foundations of dams and delineating their seeping zones (e.g., Aina et al., 1996; Bolève et al., 2012; Cho and Yeom, 2007; Panthulu et al., 2001; Sjödahl et al., 2008). The induced polarization method is an extension of the resistivity method as it provides, in addition to the electrical resistivity distribution, an additional properties characterizing the ability of porous media to store electrical charges under the application of a primary electrical field. Induced polarization has recently been applied to detect seepages in Earth dams by monitoring the change in the water content over time (Abdulsamad et al., 2019). Both resistivity and induced polarization are active geoelectrical methods for which an electrical current is injected in the ground. 
The self-potential method is a passive geophysical technique for which we measure the

74 electric field fluctuations generated by the flow of pore water in porous media. In other words, the source of current is inside the structure itself and its associated electrical field is measured remotely. This method is easy to set up and cost-effective (Revil and Jardani, 2013). It has therefore a considerable potential for the detection of seepages in dams (Rittgers et al., 2015). Several studies have investigated the effectiveness of using the self-potential method for dam inspection and monitoring. For instance, Al-Saigh et al. (1994) successfully used self-potential observations to qualitatively detect water seepages in a dam. Panthulu et al. (2001) combined the resistivity and self-potential methods to detect seepages in an earth dam built on a heterogeneous rock mass in India. The self-potential method helped them identify and delineate the seepage flow paths, which were associated to self-potential amplitudes of 10 to $15 \mathrm{mV}$. They concluded that these low self-potential observations are reflective of small seep velocities. Sheffer and Oldenburg (2007) performed a self-potential survey at an embankment in British Colombia, Canada and they found a good match between the observed and forward-modeled self-potential observations. Nevertheless, they stressed the need of developing inverse modeling strategies for adequately modeling the complex $3 \mathrm{D}$ nature of self-potential observations characteristics. Bolève et al. (2012) applied the self-potential method for monitoring a dam located in southeastern France, characterized by the presence of downstream resurgence areas that are visible to the unaided eye. Based on the self-potential observations, they performed a sensitivity analysis to estimate the magnitude of the permeability of the hydraulic pattern through which the seepages occur. Recently, Soueid Ahmed et al. (2019) implemented a 3D forward modeling numerical code for quantitatively simulating self-potential anomalies of electrokinetic nature in geological systems. They used their code to assess the effectiveness of employing the self-potential method for detecting seepages in dams by properly interpreting the self-potential signals measured on an experimental dam designed for 
geophysical experiments. The aforementioned studies show that the self-potential method is undoubtedly promising for monitoring seepages in earth dams. That said, the use of the selfpotential method for such applications remains sparse in the literature. In our opinion, the potential of the self-potential method for dams monitoring has not yet been fully investigated. Interpretation methodologies need to be developed to answer to the following two scientific questions: (i) in case of the presence of anomalous seepages in a dam structure, how the selfpotential observations could be used to invert the permeability of the preferential seepage pathways? (ii) what are the properties of dams or heterogeneous rock masses below the dam to which the self-potential signals are the most sensitive?

To answer these questions, we present a stochastic inverse scheme based on the Markov chains Monte Carlo methods (McMC) (e.g., Metropolis et al., 1953; Hastings, 1970; Sambridge and Mosegaard, 2002; Haario et al., 2006). This method is here applied to invert the selfpotential data in order to retrieve the permeability and seepage velocity of the preferential flow paths. To the best of our knowledge, this is the first time that the permeability of preferential flow paths of dams is inverted from self-potential measurements. Such study has broad implications in civil engineering. In order to test the robustness of our approach, we first test the method on a synthetic case study. The, we use new self-potential data sets performed on three different dams in field conditions to further validate the method. The strategy developed in the current paper is expected to help engineers and geophysicists in efficiently interpreting self-potential anomalies in a quantitative way to characterize seepage flow path properties in dams.

\section{Geophysical techniques}

\subsection{The self-potential method}


The self-potential method is a passive geophysical technique that measures the natural

124 electric potential anomalies that are caused by the flow of pore water in porous media. The selfpotential measurements are performed using non-polarizing electrodes that can be installed on

126 the ground surface, in boreholes, or in water. These electrodes are connected to a voltmeter 127 characterized by a high sensitivity $(\sim 0.1 \mathrm{mV})$ and a high input impedance (typically $>10$ 128 MOhm). In dams, the self-potential signals have two main causes (i) electrokinetic sources 129 generated by fluid flow in porous media, and (ii) electro-redox sources associated with the corrosion of metallic objects such as the rebar in concrete or the metallic casing of piezometers

131 (see Revil and Jardani, 2013, for specific examples). Within the framework of the current paper, 132 we focus our analysis only on the electrokinetic component. The underlying physics of streaming potential is well-established. The literature on this 134 subject is extensive (e.g., Ogilvy, 1969; Corwin, 1985; Bolève et al., 2012; Revil et al., 2012; 135 Revil and Jardani, 2013). For the sake of completeness, we only recall that the continuity 136 equation for electrical charges is given by

$$
\nabla \cdot \mathbf{j}=0
$$

138 where $\mathbf{j}\left(\mathrm{A} \mathrm{m}^{-2}\right)$ denotes the total current density. The electric current density is therefore 139 conservative in the absence of sources and sinks in the low-frequency limits of the Maxwell 140 equations. The current density is given itself by a constitutive equation as:

$$
\mathbf{j}=-\sigma \nabla \varphi+\hat{Q}_{V} \mathbf{u}
$$
where $\sigma$ denotes the electrical conductivity of the porous subsurface (in $\mathrm{S} \mathrm{m}^{-1}$ ), $\varphi$ (in

$143 \mathrm{~V}$ ) denotes the electrical (self-) potential, $\mathbf{u}\left(\mathrm{m} \mathrm{s}^{-1}\right)$ is the seepage (Darcy) velocity (given by 144 Darcy's law, see (Darcy, 1856), and (Richards, 1931)) and $\hat{Q}_{V}$ (in C m ${ }^{-3}$ ) is the effective excess 145 charge density per unit pore volume. The quantity $\hat{Q}_{V}$ is related to the permeability $k$ as 146 discussed in (Bolève et al., 2012; Jardani et al., 2006). 

equation for the self-potential:

$$
\nabla \cdot(\sigma \nabla \varphi)=\nabla \cdot\left(\hat{Q}_{V} \mathbf{u}\right)
$$

150 The right-hand-side term corresponds to the source of electrical current associated with the flow

151 of the ground water while the left-hand side corresponds to the causative solution in terms of

152 electrical (streaming or self-) potential field. The source term is modulated by the distribution

153 of the charge density $\hat{Q}_{V}$ controlled itself by the permeability and the salinity (the influence of

154 the latter is much weaker than the influence of the permeability, see Jougnot et al., 2019). The

155 left-hand side of equation (3) is modulated by the electrical conductivity $\sigma$. The electrical

156 conductivity field is therefore an important parameter for modeling the self-potential forward

157 response of a dam. It can be independently obtained using electrical resistivity tomography.

158 Furthermore, analyzing the anomalies of the electrical resistivity field may give insights about

159 the presence of seepage areas in dams as discussed below in section 2.2 (see also (Ikard et al., 160 2012)).

Solving the self-potential problem consists of first solving the groundwater flow equation to compute the seepage (Darcy) velocity $\mathbf{u}$ and then using the distribution of $\mathbf{u}$ to compute the right hand-side of the electric potential equation and then the electrical potential

164 distribution (e.g., Jardani et al., 2006).

\subsection{Electrical resistivity tomography}

Electrical resistivity measures the ability of a material to conduct or transmit an electric current, i.e. the flow of charge carriers. Electrical Resistivity Tomography (ERT) is a

169 geophysical method that measures the resistivity distribution of the medium (e.g., Loke, 2004).

170 It consists of injecting an electric current between two electrodes A and B and measuring the 171 associated electrical field of this medium (i.e., the resulting voltage distribution) between a set 
172 of dipoles composed of voltage electrode bipoles $\mathrm{M}$ and $\mathrm{N}$ (all the electrodes are generally

173 stainless steel electrodes). For this goal, we use a network of electrodes and a resistivity meter.

174 In an isotropic heterogeneous medium, this forward operator is given by the following field

175 equation:

176

$$
-\nabla \cdot(\sigma \nabla \varphi)=I \delta\left(X-X_{0}\right)
$$

177 where $\sigma$ (in $\mathrm{S} \mathrm{m}^{-1}$ ) is the electrical conductivity (its reverse is the electrical resistivity), $\varphi$ is

178 the electrical potential (voltage in V) and $I$ (in A) denotes the injected current between the

179 current electrodes $\mathrm{A}$ and $\mathrm{B}, \delta$ is the Dirac distribution, $X$ represents the spatial locations and

$180 X_{0}$ represents the spatial coordinates of the current injection electrodes. In essence, equation

181 (4) is similar to equation (3) except that the source is here active. In the field, the equipment 182 provides the resistance or the apparent resistivity. These quantities are obtained from the 183 solution of Equation (4) as:

$$
R_{a}=\frac{\Delta \varphi_{M N}}{I}
$$

$$
\rho_{a}=G R_{a}
$$

where $\Delta \varphi_{M N}$ denotes the difference of potential recorded between the electrodes $\mathrm{M}$ and $\mathrm{N}, R_{a}$

187 (in $\Omega$ ) is the measured resistance, $\rho_{a}$ (in $\Omega . m$ ) is the apparent resistivity and $G$ is the 188 geometric factor (which depends on the electrode configuration). Imaging the electrical 189 resistivity spatial distribution can be formulated as an inverse problem whose solution is 190 obtained through the minimization of an objective function, which reduces the misfit between 191 the observed and computed resistances or apparent resistivities plus a regularization term 192 introduced to ensure the stability of the inverse problem (Günther et al., 2006; Loke and Barker, 193 1996; Soueid Ahmed et al., 2018; Tikhonov, 1943). For more details regarding the underlying 194 physics and principle of ERT, the reader is invited to refer to the rich literature on this subject 
195 (for instance Daily et al., 2004; Edwards, 1977; Herman, 2001; Revil et al., 2012, just to cite 196 few references).

\subsection{Hydraulic parameters estimation}

Retrieving the permeability field of a preferential groundwater pathway in a dam or its

200 foundation can be mathematically cast as an in inverse problem like for electrical resistivity tomography. It consists of inferring the permeability values from the self-potential measurements generally collected upstream and downstream the dam. The inverse problem is formulated as an optimization problem whose solution is the most optimal permeability model that reproduces the self-potential observations, knowing the electrical resistivity field. Instead of using conventional deterministic methods such as the Gauss-Newton method, we use here an McMC sampler to solve the inverse problem (e.g., Haario et al., 2006, 2004; Jardani et al., 2012). Notwithstanding the fact that McMC samplers require the deployment of intensive computational resources, we opted for this approach because it does not require assembling sensitivity matrices and is also more robust for avoiding the inverse algorithm getting trapped in local minima. In addition, the model solution provided by the McMC algorithm does not

211 have a strong dependence on the initial model parameter in contrast to gradient based methods (e.g., Mosegaard and Tarantola, 1995; Sambridge and Mosegaard, 2002). In this context, we

214 is the data vector, $\mathbf{m}\left(m_{n} \times 1\right)$ is the unknown vector, $n_{d}$ and $m_{n}$ are the numbers of measurements and unknowns, respectively. In our case, $\mathbf{m}$ is the vector of hydraulic properties of the preferential flow path (i.e., the permeability and the pressure of the water outlet area).

$$
\pi(\mathbf{m} \mid \mathbf{d}) \propto P(\mathbf{d} \mid \mathbf{m}) P_{0}(\mathbf{m})
$$


where $P_{0}(\mathbf{m})$ denotes the prior probability density of the model parameters $\mathbf{m}$.

The conditional probability density $P(\mathbf{d} \mid \mathbf{m})$ of $\mathbf{m}$ given $\mathbf{d}$ is given by:

$$
P(\mathbf{d} \mid \mathbf{m})=\frac{1}{\left((2 \pi)^{n_{d}} \operatorname{det} \mathbf{R}\right)^{\frac{1}{2}}} \exp \left(-\frac{1}{2}\left(\mathbf{d}-F_{\varphi}(\mathbf{m})\right)^{T} \mathbf{R}^{-1}\left(\mathbf{d}-F_{\varphi}(\mathbf{m})\right)\right)
$$

The prior probability density of the model parameters $\mathbf{m}$ is given by:

$$
P_{0}(\mathbf{m})=\frac{1}{\left((2 \pi)^{m_{m}} \operatorname{det} \mathbf{C}\right)^{\frac{1}{2}}} \exp \left(-\frac{1}{2}\left(\mathbf{m}-\mathbf{m}_{0}\right)^{T} \mathbf{C}^{-1}\left(\mathbf{m}-\mathbf{m}_{0}\right)\right),
$$

where $F_{\varphi}(\cdot)$ is the streaming potential forward problem, $\mathbf{R}\left(n_{d} \times n_{d}\right)$ is the data covariance

matrix, $\mathbf{C}\left(m_{m} \times m_{m}\right)$ is the model covariance matrix which takes into account the uncertainties

related to the choice of the prior model $\mathbf{m}_{0}$.

McMC approaches are iterative processes, which use random walks to sample the values of the model parameter. At each iteration, the choice of the next state is only based on the current state. This ensures lower dependence on the initial model. Generally, the starting realizations are discarded and then the random walker moves toward the regions of high probability for the model parameters. As indicated by Sternberg (1979), the McMC approaches are more efficient than Monte Carlo methods (which generate samples independently) because

234 the chains stay in the regions of high posterior probability of the model parameters space. In 235 the current work, we use the Metropolis-Hastings $(\mathrm{MH})$ algorithm, which is a variant of the 236 McMC algorithms. The choice of this algorithm is mainly motivated by its simplicity and 237 flexibility. It was first introduced by Metropolis et al. (1953) and generalized by Hastings 238 (1970). The MH algorithm is based on the three following steps:

239 1. Choose an initial model $\mathbf{m}_{\mathbf{0}}$.

240 2. Compute the acceptance probability: 


$$
\alpha\left(\mathbf{m}^{\mathrm{i}-1}, \mathbf{m}^{*}\right)=\min \left(1, \frac{\pi\left(\mathbf{m}^{*}\right)}{\pi\left(\mathbf{m}^{\mathbf{i}-1}\right)}\right)
$$

2423 . Set $\mathbf{m}^{\mathrm{i}}=\mathbf{m}^{*}$ with the probability $\alpha$ otherwise set $\mathbf{m}^{\mathrm{i}}=\mathbf{m}^{\mathrm{i}-1}$ with the probability $1-\alpha$. The 243 index i denotes the current iteration. Steps 2 and 3 are repeated $N_{t}$ times, where $N_{t}$ denotes 244 the total number of iterations.

\section{Case studies}

\subsection{Methodology}

In this section, we apply our approach on three case studies. We first wish to validate our approach using a synthetic case. Regarding the three case studies discussed below, we perform new large scale self-potential surveys. Resistivity measurements were also performed to assist the interpretation of the self-potential signals. All the case studies have the same goal,

i.e. detecting the potential presence of seepage flow paths and retrieving their mean permeability. The forward problem is solved using the finite element software Comsol Multiphysics and we implement the inverse procedure in Matlab. In our simulation approach, each component of the dam (i.e., its core, structure, resistivity of the water of the reservoir, foundation geometry and properties) as well as the seepage along a preferential flow path are modeled. Each of these components is identified through their electrical property and permeability. Geotechnical measurements and resistivity profiles can help estimating these properties for the components of the dam. The big challenge resides in finding the permeability 260 of the preferential flow path, which can be a pretty difficult task using conventional geotechnical techniques.

On the other hand, the geometry of the conduit used to simulate the seepage flow path has no influence on the self-potential magnitudes and therefore, we do not focus in this paper

264 on estimating the exact shape of the seepage flow path. That said, in the last case study, we use 
an inverse procedure for approximating the shape of the fluid path based on the self-potential observations.

Another issue of interest that is worth noting is the choice of the boundary conditions for solving the forward model problem. For the electric problem, insulating boundary conditions are imposed at the dam/air interface (i.e., $\hat{\mathbf{n}} \cdot \mathbf{j}=0$, where $\hat{\mathbf{n}}$ is the outward normal

at the remaining boundaries. For the hydraulic problem, we impose the atmospheric pressure on the top of the dam, i.e., on all the boundaries that are in contact with the atmosphere. At the inlet boundary of the preferential flow path, the hydrostatic pressure of the water reservoir is imposed as a fluid pressure condition. At the outlet, the fluid pressure is unknown and therefore its value inverted along with the permeability of the seepage flow path. Taking into account these pressures is necessary for computing the hydraulic gradient which indeed has an important influence on the magnitude of the self-potential observations. For all the simulations, the domain of interest is padded with infinite element domains to avoid the influence of the boundary conditions on the electric potential distribution and the reference electrode has been 280 placed far away from the from dam.

\section{$281 \quad 3.2$ Synthetic test}

We first validate our approach on a synthetic earth dam suffering from a leakage problem. We use the synthetic self-potential observations computed on the dam (using forward modeling) to retrieve the permeability of the presumed preferential flow path going through the 285 dam foundation. The true hydraulic and electric properties of the dam are known (see Table 1) 286 even though during the inverse process the permeability of the seepage flow path is assumed to 287 be unknown. The dam has a length of $72 \mathrm{~m}$ and a height of $10 \mathrm{~m}$, includes an impermeable clay 288 core and contains a water reservoir whose level reaches $7 \mathrm{~m}$. Figure 1a illustrates the geometry 289 of the dam. The true permeability of the preferential flow path is $10^{-10} \mathrm{~m}^{2}$ and the seepage 
velocity within it is $1.1 \times 10^{-4} \mathrm{~m} \mathrm{~s}^{-1}$. We recall that our goal is to retrieve these parameters from

291 the self-potential measurements observed on the dam. The true self-potential distribution of the 292 dam obtained using the true hydraulic and electric parameters are shown on Figure 1b. It clearly reveals the presence of a $-27 \mathrm{mV}$ self-potential anomaly at the seepage area and a $+20 \mathrm{mV}$ at the resurgence area. The true data are contaminated with a $2 \%$ Gaussian white noise. Using the proposed McMC inversion approach, we launch 10,000 iterations starting the initial permeability field at $10^{-12.5} \mathrm{~m}^{2}$. The best permeability estimate is chosen as the mean of the McMC chain which is $10^{-10.28} \mathrm{~m}^{2}$. The computed velocity within the seepage flow path is $8.3 \times 10^{-5} \mathrm{~m} \mathrm{~s}^{-1}$. These values are close to the true ones, indicating that our methodology is fairly reliable. Furthermore, the computed self-potential signal reproduces with high fidelity the true one (see Figure1 c), showing that the inverse algorithm has converged. The associated coefficient of correlation is $\mathrm{R}^{2}=0.99$ and the amplitudes of the downstream and upstream observed self-potential anomalies are well recovered.

\subsection{Case study 1}

In this field example, we consider a hydroelectric dam built on a $340 \mathrm{~km}$ long river located in Africa. The priming of this dam was done in 1987 and its reservoir retains $2 \mathrm{~km}^{3}$. The dam is composed of the following structures: (i) a right bank dyke having a length of 2,780 $\mathrm{m}$ and $12 \mathrm{~m}$ of height, (ii) a left bank dyke having a length of 1,660 $\mathrm{m}$ and $21 \mathrm{~m}$ of height. (iii) A main rockfill dyke with an earth core which is $430 \mathrm{~m}$ long and $50 \mathrm{~m}$ high. (iv) A moveable dam including 4 intake openings having a length $56 \mathrm{~m}$ and a height of $22 \mathrm{~m}$. (v) A gravity dam having 2 intake structures and bottom discharge system. This dam is $45 \mathrm{~m}$ long and $38 \mathrm{~m}$ high. From a geological point of view, the test site is located in the basement rocks of the Precambrian formation. It contains metamorphic rocks such as gneiss, shales, diorite, and 314 amphibolite. The two supports of the dam are covered by scree slopes whose thickness 
approximately varies between $1 \mathrm{~m}$ and $3 \mathrm{~m}$. This layer is made up of rock fragments (gneiss and quartz) as well as clayey materials. Beyond the scree slopes, the rock is severely altered and takes the form of a sandy-clay loam with some quartzite fragments. In the river bed, the fresh rock often outcrops and is locally covered by fresh sandy-gravelly alluvium. The main dike contains a lateritic core and is covered by an upstream filter and 2 downstream filters. Its foundation is composed of gneiss and is highly fractured due to the intrusion of quartz veins and to hydrothermal alteration as well. The foundations of the left bank and right bank dikes are from lateritic materials. Their cores are made up of a mixture of clay, silt and sand.

Geoelectrical surveys (ERT and SP) have been performed to better characterize the dam structures and also to inspect the presence of seepages in the dam. The ERT measurements were performed downstream on a line of $1.4 \mathrm{~km}$ along the left bank dike and another line of 2.3 $\mathrm{km}$ along the right bank dike. We used a network of 64 electrodes, spaced from each another by $2.5 \mathrm{~m}$ downstream and by $5 \mathrm{~m}$ at the crest of the dam. This high-resolution array of measurements at the toe of the dam aims at better detecting and depicting potential seepage areas in the dam structures. We use the dipole-dipole configuration for acquiring the resistivity measurements because this protocol is very sensitive to the lateral variations of the resistivity and thus is useful for detecting resistivity anomalies associated with seepages in dams. The selfpotential profiles were implemented downstream and upstream on the dam. This was done to

334 be able to localize the seepage areas through their anomalies which are expected to be negative 335 in the inflow area and positive in the outflow area. Downstream, the self-potential 336 measurements were collected each $2.5 \mathrm{~m}$ (at the same location to the resistivity electrodes) for 337 a total distance of $8.5 \mathrm{~km}$. Upstream, the self-potential measurements were collected on water 338 i.e., in the reservoir at approximatively few meters from the bottom of it. We will only consider 339 the left bank because it is highly suspected to contain seepage flow path due to the presence of 
visible flood areas at some places at the downstream foot of this dike. Figure 2 shows the

341 resistivity and self-potential profiles realized on the left bank. These profiles are $1.5 \mathrm{~km}$ long

342 but we only show the parts that exhibit the anomalies of interest. Figure 2 indicates that the

343 shallow layer of the medium is globally conductive, while the foundation is resistive. Between

344 the position $1,450 \mathrm{~m}$ and $1,490 \mathrm{~m}$ we can observe some conductive anomalies (less than 200

345 Ohm $\mathrm{m}$ ), which are characteristic of alteration zones that have high permeability and can be

346 associated with preferential seepage paths. Examining the self-potential observations puts in

347 evidence a positive peak $(+30$ to $+35 \mathrm{mV})$ that is clearly greater than the average. Interestingly,

348 this peak is located exactly at the place where the conductive anomalies are observed. In

349 addition, our self-potential measurements have an excellent reproducibility and thus, we highly

350 suspect the presence of a seepage area over there. Instead of simply stopping at this stage of

351 observation, we propose to go further by efficiently interpreting the self-potential observations

352 that we acquired. We will first perform a sensitivity analysis based on varying the resistivity

353 and permeability of the components of the dam (i.e., the structure, water of the reservoir, and

354 the preferential flow path) to see which of them has the most influence on the self-potential

355 signals measured upstream and downstream. Although this sensitivity analysis is basic and only

356 consists of only a parametric sweep on the physical parameters' values, it nevertheless gives a

357 general good understanding on how these parameters influence the self-potential magnitudes.

358 The dam is modeled as the domain represented in Figure 3.

If we suppose that in the conduit (i.e., seepage flow path), the surface conductivity

360 is negligible (no presence of clayey minerals with high specific surface), Archie's law gives us

361 a good approximation of the resistivity of the fully saturated porous medium which will be 362 around $400 \mathrm{Ohm} \mathrm{m}$. In the first sensitivity analysis, we vary the permeability of the conduit and 363 see which permeability can reproduce the observed self-potential anomalies. We vary the 364 permeability over the following set of values (expressed in $\mathrm{m}^{2}$ ): $\left\{10^{-10}, 10^{-9}, 10^{-8}, 10^{-7}, 10^{-6}, 10^{-}\right.$ 
$\left.{ }^{5}, 10^{-4}, 10^{-3}, 10^{-2}\right\}$. The results of such test are represented in Figure $4 \mathrm{a}$. One can easily see that

366 the permeability that reproduces the self-potential magnitudes (i.e., $-5 \mathrm{mV}$ upstream and 30 to

$36735 \mathrm{mV}$ downstream) is comprised between $10^{-9}$ and $10^{-8} \mathrm{~m}^{2}$. We fix the permeability of the

368 conduit at $10^{-8} \mathrm{~m}^{2}$ and we vary resistivity of the conduit within the values: $\{30,200,300,400$,

$369500,600,700,800,900,1000\}$ in Ohm m. As illustrated in Figure 4b, an electrical resistivity

370 of around $400 \mathrm{Ohm} \mathrm{m}$ reproduces with high confidence the observed self-potential anomalies.

371 We also notice that from $400 \mathrm{Ohm} \mathrm{m}$, the self-potential magnitudes do not very too much.

372 Another component of interest is the dam structure itself and it is interesting to see to how this

373 massive part of the dam contributes to the self-potential observation characteristics. We first fix

374 the resistivity of the structure to $800 \mathrm{Ohm} \mathrm{m}$ (this value is taken from the electrical resistivity

375 profile) then we switch the permeability of the structure in this set of values : $\left\{10^{-20}, 10^{-19}, 10^{-}\right.$

$\left.376{ }^{18}, 10^{-17}, 10^{-16}, 10^{-15}, 10^{-14}, 10^{-13}, 10^{-12}\right\}$ in $\mathrm{m}^{2}$. Figure 5 a illustrates the results of such experiment.

377 We notice that the self-potential signals vary a little with respect to the variations of the

378 permeability of the structure. Similarly, we perform a sensitivity analysis on the resistivity of

379 the structure. Its permeability is fixed at $10^{-17} \mathrm{~m}^{2}$ and its resistivity varies within this set of

380 values: $\{100,200,300,400,500,600,700,800,900,1000,1100,1200\}$ (in Ohm m). Figure

$3815 \mathrm{~b}$ represents the self-potential anomalies obtained with this resistivity set of values. Indeed,

382 the self-potential amplitudes do not strongly vary unless for conductive media. This sensitivity

383 analysis tells us that the permeability of the structure does not seem to be the parameter that

384 influences the most the self-potential magnitudes. The resistivity of the structure has a greater

385 influence on the observed self-potential signal.

386 We move now to the sensitivity analysis on the salinity (identified by electrical

387 resistivity) of the water of the reservoir. In fact, the resistivity of the water was measured during

388 the field campaign, and was found to be around $50 \mathrm{Ohm} \mathrm{m}$. The purpose of this sensitivity

389 analysis is to make sure that this value is plausible and to see the influence of the resistivity of 
the water on the self-potential signal. We vary the resistivity of the water in the following set of values: $\{10,12.5,16.7,25,50,100,200,1000\}$ Ohm m. Figure 6 shows that the observed self-potential magnitudes are retrieved with a resistivity ranging from 50 to $100 \mathrm{Ohm}$ m which indicates the correctness of the magnitude of the measured resistivity. inverse modeling as explained in section 2 . The sensitivity analysis has established that the permeability of the conduit should be between $10^{-9} \mathrm{~m}^{2}$ and $10^{-8} \mathrm{~m}^{2}$. We propose to invert for the value of the permeability from self-potential measurements and to see how well it compares with the range of magnitudes given by the sensitivity analysis. Since the resolution of the forward problem requires the knowledge of the pressure at the resurgence area (set as a boundary condition), we invert for the value of this pressure along with the permeability. The inverse problem ran during $12 \mathrm{~h}$ on a 32 cores desktop, using a total number of 30,000 iterations. This means that the forward problem needs to be solved 30,000 times. The best solution is chosen as the mean of the Markov chains associated to the permeability and pressure values.

404 We obtain $5 \times 10^{-9} \mathrm{~m}^{2}$ for the permeability of the conduit and a pressure of $4500 \mathrm{~Pa}$ at its outlet. 405 This permeability value indeed falls within the range of magnitudes obtained by the sensitivity 406 analysis.

Furthermore, the reconstructed permeability and pressure reproduce the observed self-potential anomalies with high fidelity. Indeed, the simulated self-potential magnitude in 409 the reservoir is around $-5 \mathrm{mV}$ at $1 \mathrm{~m}$ from the bottom of the reservoir while the simulated is 410 anomaly is around $30 \mathrm{mV}$ downstream (see Figure 7a). The coefficient of correlation of the 411 observed self-potential data versus the true ones is 0.9 which indicates an excellent match 412 between them, as indicated by Figure $7 \mathrm{~b}$. Once the hydraulic properties of the dam have been 413 evaluated, one can compute an important parameter that is, the seepage velocity. In our case 414 study, this seepage velocity is $0.019 \mathrm{~m} / \mathrm{s}$. 


\subsection{Case study 2}

The second case deals with a hydroelectric dam located in west Africa. This dam was first operated in the 80 's. It is $3615 \mathrm{~m}$ long and its water reservoir has an impounding capacity of 8.4 billion $\mathrm{m}^{3}$. The dam is composed of the following facilities: (i) a $3615 \mathrm{~m}$ long main dike that is $37 \mathrm{~m}$ high above the river bed, (ii) a secondary dike having a length of 1985 $\mathrm{m}$ and a maximum height of $20 \mathrm{~m}$, (iii) a closing pass dike. (iv) A $3480 \mathrm{~m}$ tailrace, excavated with rocky formations.

The site is located in a region that is globally very eroded and severely weathered.

The dam itself (i.e., main and secondary dikes) is built on a very heterogonous rocky substratum, distributed as follows: (i) right bank of the main dike: shale formation composed of schists and micaschists, called «upstream formation », (ii) River bed (main dike): called the «transition formation », it is the formation of composed amphobolites, aplite rodes and very hard lepptynite, (iii) left bank of the main dike and secondary dike: granite with two micas (biotite and muscovite) with ferromagnesian mineral enclaves, (iv) edge of the left bank of the secondary dike: formation of shales, called the « downstream formation ».

A seepage area has been identified in the right bank of the main dike and unintended water puddles are clearly visible at the bottom of the dike. Self-potential measurements were collected upstream (i.e., in the water reservoir) on a distance of $1.5 \mathrm{~km}$ and downstream on a

$4341.5 \mathrm{~km}$ profile long and $5 \mathrm{~m}$ between each electrode. A total of 2,000 self-potential 435 measurements were collected. 1,800 resistivity measurements were performed on a $1.5 \mathrm{~km}$ 436 profile. We used a dipole-dipole protocol with an electrode interval of $5 \mathrm{~m}$. The self-potential measurements are represented in Figure 8.

Similar to the previous case studies, we performed a sensitivity analysis on the 439 electrical properties of the different components of the dam. The geometry used for the 
numerical simulations is represented in Figure 9. The water reservoir level reaches $20 \mathrm{~m}$. The

441 observed self-potential magnitudes are around $-15 \mathrm{mV}$ at the seepage area (i.e., in the reservoir)

442 and $+50 \mathrm{mV}$ downstream at the resurgence area. The first sensitivity analysis consisted in fixing

443 the resistivity of the preferential flow path at $150 \mathrm{Ohm} \mathrm{m}$ (this value is deduced from the

444 resistivity profile) and then we switch the permeability values in the set $\left\{10^{-10}, 10^{-9}, 10^{-8}, 10^{-7}\right.$,

$\left.44510^{-6}, 10^{-5}, 10^{-4}, 10^{-3}, 10^{-2}\right\}$ expressed in $\mathrm{m}^{2}$. The results of such test are reported in Figure 10a.

446 One can notice that the downstream and upstream self-potential magnitudes are reproduced

447 with a permeability interval of $\left[10^{-9}, 10^{-8}\right]$. We will perform the inversion of the permeability

448 of the conduit later on to validate this permeability range. We now fix the permeability of the

449 conduit at $10^{-9} \mathrm{~m}^{2}$ and vary the electrical resistivity within these values: $\{30,200,300,400$,

$450500,600,700,800,900,1000\}$ in Ohm m. As illustrated in Figure 10b, an electrical resistivity

451 of 100-150 Ohm $\mathrm{m}$ allows for reconstructing the observed self-potential amplitudes. In addition,

452 this value is in well accordance with the resistivity tomogram which shows a 150 Ohm $\mathrm{m}$

453 anomaly. We presently move on to the sensitivity analysis on the properties of the main

454 structure of the dam. We assigned a resistivity of $2000 \mathrm{Ohm} \mathrm{m}$ to the main structure of the dam.

455 This value is suitable for this type of material and is confirmed by the ERT. Then the 456 permeability of the structure is switched within the following values (expressed in $\left.\mathrm{m}^{2}\right):\left\{10^{-}\right.$ $\left.457{ }^{20}, 10^{-19}, 10^{-18}, 10^{-17}, 10^{-16}, 10^{-15}, 10^{-14}, 10^{-13}, 10^{-12}\right\}$. As illustrated in Figure 11a, the permeability of 458 the structure does not have a major impact on the self-potential signal, which remains quite 459 constant despite the wide range of permeability that we used. The resistivity sensitivity analysis 460 is performed by fixing the permeability at $10^{-15} \mathrm{~m}^{2}$ (see Table 1 ).

The resistivity is varied within this set of magnitudes: $\{100,200,300,400,500,600$,

$462700,800,900,1000,1100,1200\}$ in Ohm m. Figure 11b shows the downstream and upstream generated self-potential anomalies. Indeed, unless we are in the presence of very conductive media, the magnitudes of self-potential anomalies do not vary significantly and are almost 
constant. This suggests that the resistivity of the dam structure does not need to be known with high precision, and having relatively wide but reasonable resistivity range will not affect the numerical modeling of the self-potential signatures.

We discuss now the effect of the water resistivity on the self-potential signal measured on the dam. This water sensitivity analysis on the resistivity parameter was important for approximating the resistivity that should be assigned to the reservoir in our modeling. The water resistivity is varied within the following set of values: $\{10,12.5,16.7,25,50,100,200$, $1000\}$ in Ohm m. As illustrated in Figure 12, one can notice that the observed self-potential anomalies (i.e., $-15 \mathrm{mV}$ upstream and $+50 \mathrm{mV}$ ) are well reproduced for resistivity ranging from 12.5 to $100 \mathrm{Ohm} \mathrm{m}$. In the field, the measured resistivity was $100 \mathrm{Ohm} \mathrm{m}$, therefore this value seems quite reasonable for modeling the effect of water salinity on the self-potential signal.

Once the sensitivity analysis has been performed, we move on to the estimation of the hydraulic properties of the preferential flow path. The sensitivity analysis has established that the likely value of the permeability is between $10^{-9} \mathrm{~m}^{2}$ and $10^{-8} \mathrm{~m}^{2}$. The inversion that we run is performed to check by another means the accuracy of this estimation. We ran 30,000 McMC simulations to reach the convergence of the inverse algorithm. The algorithm gives 2.5 $10^{-9} \mathrm{~m}^{2}$ for the permeability of the seepage flow path and $2843.9 \mathrm{~Pa}$ at its exit. These values indeed allow for reproducing the values of the observed anomalies i.e. $-15 \mathrm{mV}$ in the vicinity of the bottom of the water reservoir and +50 to $+60 \mathrm{mV}$ downstream, at the resurgence area (see Figure 13a). This is in accordance with the physics behind the self-potential method. Indeed, the self-potential anomalies are expected to be negative upstream around the seepage area and positive upstream around the resurgence area.

The comparison of the observed self-potential signal against the simulated one obtained using the best hydraulic properties given by the inverse modeling, shows a very good match between both signals (see Figure 13b). The corresponding coefficient of correlation is 
$490 \mathrm{R}^{2}=0.99$. The computed velocity within the seepage flow path is obtained from the inverted 491 hydraulic properties and is estimated to be $1.510^{-3} \mathrm{~m} . \mathrm{s}^{-1}$.

\subsection{Case study 3}

The third dam that we are working on in this case study is located in West Africa as well. It was built in 1980. Its reservoir has a volume of 38.5 billion $\mathrm{m}^{3}$ and the water level within it reaches $15 \mathrm{~m}$. The earth dam consists on homogeneous backfill bank and rockfill on upstream side. The total length of the dam is $1,164 \mathrm{~m}$ for a maximum high of $31 \mathrm{~m}$ above foundation.

Geological structure of the site contains four main geological units from the top to the bottom:

(i) lateritic cuirass (it is a very hard rock partly constituting the dam foundation), (ii) lateritic carapace (composed of gravel with clay matrix or lateritic clays). The cumulative thickness of these two units is less than $10 \mathrm{~m}$, (iii) dolerite arena (predominantly sandy-clay. It is thicker on the left bank where it can reach $25 \mathrm{~m}$ thick against $10 \mathrm{~m}$ ) on the right shore, (iv) dolerite appears progressively less weathered with depth or directly healthy under the dolerite arena. Its roof is not uniform and presents locally faulted passages. The Lateritic cuirass and carapace units are both porous in the form of canaliculi whose diameter, according to information provided, can reach centimeters to decimeters. Constituting the upstream and downstream foundation of the dam (located in contact with the clay core of the dam as well), we can assume that these two units are responsible of preferential seeps.

In order to model the dam environment, we geometrically represent each of the geological formations of the dam site (see Figure 14) and we assign to each of them its physical

511 properties as reported in Table 2. The self-potential measurements performed on the dam revealed the presence of a seepage area characterized by negative self-potential anomalies upstream of the dam, reaching -40 to $-50 \mathrm{mV}$ and $+150 \mathrm{mV}$ self-potential anomalies observed

514 downstream of the dam (see Figure 15). 
In this case study, we adopt a different strategy as we approximate the shape of the seepage fluid path. We first compute the source current density $\mathbf{j}_{s}$ from the self-potential

517 observations by solving an inverse problem. This inverse problem is linear and can be readily 518 solved as its resolution does not require the use of any interactive process. For the sake of 519 brevity, we will not discuss here the algorithm used for the linear inversion. The reader who 520 desires more details about this inverse strategy is invited to refer to Soueid Ahmed et al. (2013). 521 The estimation of the current density is represented in Figure 15b. One can notice that this 522 current density distribution shows an area of high magnitude which presumably corresponds to 523 the area where the anomalous seepage occurs. Therefore, this gives the possibility of delineating 524 the seepage flow path.

As for the previous case studies, we will do a sensitivity analysis on the properties of the dam. We underline that this dam has a homogenous structure (i.e., it does not contain a low permeability core) which is well characterized (see Table 3) so we did not see a rationale 528 for performing a sensitivity analysis on its structure as done for the previous studied dams. The sensitivity analysis is restricted to the seepage flow path and water properties. The resistivity tomogram identified an anomaly of around $800 \mathrm{Ohm} \mathrm{m}$, thus we chose it to be the resistivity of 531 the seepage preferential flow path. The permeability (expressed in $\mathrm{m}^{2}$ ) is varied with the 532 following set of values: $\left\{10^{-10}, 10^{-9}, 10^{-8}, 10^{-7}, 10^{-6}, 10^{-5}, 10^{-4}, 10^{-3}, 10^{-2}\right\}$. The results of such 533 sensitivity analysis are illustrated in Figure 16a. One can see that the observed self-potential 534 anomalies can be reproduced by a permeability ranging between $10^{-10} \mathrm{~m}^{2}$ and $10^{-9} \mathrm{~m}^{2}$. Let us now fix this permeability at $10^{-9} \mathrm{~m}^{2}$ for the sake of performing a sensitivity analysis on the 536 resistivity of the preferential flow path. We vary the resistivity within the set of values: $\{30$, $537200,300,400,500,600,700,800,900,1000\}$ in Ohm m. As expected, a resistivity comprised 538 between $600 \mathrm{Ohm} \mathrm{m}$ and $900 \mathrm{Ohm}$ m satisfactorily reproduced the observed self-potential 539 anomalies, that is -10 to $-15 \mathrm{mV}$ upstream and $50 \mathrm{mV}$ downstream (see Figure $16 \mathrm{~b}$ ). Then we 
performed a sensitivity analysis on the resistivity of the water of the reservoir. We vary the

541 resistivity of the pore water within the set of values given by: $\{10,12.5,16.7,25,50,100,200$,

$5421000\}$ (in Ohm m). As shown in Figure 16c, the downstream and upstream self-potential 543 anomalies are reproduced with a resistivity ranging from $10^{2.4}$ to $10^{3} \mathrm{Ohm} \mathrm{m}$, or equivalently 544 from 251 to $1000 \mathrm{Ohm} \mathrm{m}$. We consider now the estimation of the permeability of the 545 preferential flow path. The sensitivity study has shown that the value of the permeability is 546 likely comprised between $10^{-10} \mathrm{~m}^{2}$ and $10^{-9} \mathrm{~m}^{2}$. After 30,000 simulations, the McMC algorithm converged towards a permeability of $510^{-10} \mathrm{~m}^{2}$ and an outlet pressure of $2946 \mathrm{~Pa}$. As illustrated in Figure $17 \mathrm{a}$ and $17 \mathrm{~b}$, the recovered permeability field reconstructs with high fidelity the observed self-potential anomalies. The coefficient of correlation between the observed and simulated self-potential signals is $\mathrm{R}^{2}=0.996$. The computed self-potential distribution clearly reveals a negative upstream anomaly and a positive downstream one, which are reflective of the presence of a seepage flow path. The flow velocity within the seepage flow path is $4.610^{-4}$ $\mathrm{m} \cdot \mathrm{s}^{-1}$.

The sensitivity analysis that we performed on the three dams gave us insights about the characteristics of self-potential signals in dams. From the three studied dams, we conclude that estimating the permeability of the seepage flow path needs to be done with high accuracy as this factor directly affects the magnitudes of the self-potential anomalies. In contrast to the narrow range of permeability, a relatively wide range of resistivity values reproduces well the observed self-potential anomalies. Indeed, the resistivity magnitudes revealed by the resistivity

560 for the seepage areas give accurate estimation of the observed self-potential magnitudes. This 561 suggests that using the resistivity field given by the resistivity as input in the self-potential simulations is acceptable and will not lead to significant errors in the simulation of the selfpotential signal. On the other hand, the permeability of the main structure of the dam does not 564 seem to have a strong impact on the self-potential signals while its resistivity has a stronger 
impact on the self-potential signal, especially when this resistivity is underestimated. In this

566 case, the self-potential signal becomes weak and the computed signal does not match well with

567 the observed one. The sensitivity analysis has (besides checking the accuracy of the water

568 resistivity measured in the field), underlined the importance of having reliable measures of this

569 property for a more accurate approximation of the self-potential signatures.

As a final note, we underline the fact that we have computed the Reynolds number for

571 the three case studies to see under which regime flow we are working. The Reynolds number

572 is, $0.3,0.19$ and 0.3 for the three cases, respectively. Indeed, these low values of the Reynolds

573 number suggest that we are under the laminar flow regime and therefore the Reynolds number

574 has a very weak influence on the self-potential signatures and can be neglected.

575 The case studies presented above show the effectiveness of the SP method as an efficient

576 nondestructive and passive technique for dams' prospection, which has the twofold advantage

577 of being straightforward to set up and financially cheap. Indeed, thanks to its high sensitivity to

578 the groundwater flow, the SP method can provide valuable information regarding the hydraulic

579 texture of the subsurface and the behavior of the water flow within it. That said, the literature

580 on the use of the SP method for dams investigations, is mostly restricted to quantitative studies

581 in which the SP method is simply used as an indicator of the presence of seeps in the structure

582 of the dam. The current work helps filling this interpretation gap by providing more powerful

583 numerical approaches for taking full advantage of the SP data and though obtaining key

584 information such as accurate delimitation of the seepage area, the velocity of the seepage flow

585 as well as the permeability of the seepage flow path. Therefore, the methodology that we have

586 developed is of high interest especially for the engineers working on the prospection and 587 surveillance of hydraulic structures such as dams and embankments.

\section{Conclusion}


The self-potential method appears as a suitable method for large-scale investigation of 591 earth dams. We have developed a strategy for interpreting quantitatively self-potential 592 observations in achieving a two-fold objective: (i) putting in evidence the presence of an 593 anomalous seepage in the structure or foundation of a given dam, (ii) estimating the 594 permeability of the seepage flow paths and the flow velocity within them. Being able to evaluate 595 such properties is of paramount importance for dam managers to evaluate suffusion phenomena. 596 The inverse methodology that we propose is based on the McMC approach that has the 597 advantage of not requiring assembly of the sensitivity matrix, which is a daunting task 598 especially when working on large-scale applications. We have validated the effectiveness and 599 robustness of our inverse scheme on a synthetic test and several real field applications in which 600 the self-potential method clearly exhibits the seepage areas and successfully allows for the 601 estimation of the hydraulic properties of the seepage flow paths. Our study shows also the importance of jointly using other techniques in addition to the self-potential method to strengthen the interpretation of self-potential anomalies. In our case, the resistivity tomography

604 method was used to connect the resistivity anomalies associated to the presence of seepages to 605 the self-potential signatures and to provide the electrical resistivity field, which is an input for 606 the forward modeling. Future works should be geared towards the combination of the self607 potential and induced polarization methods. The latter could be used to infer water content and 608 saturation through the dam structure. We also see an opportunity for using deep learning 609 algorithms for better delineation of the seepage flow paths.

611 Acknowledgments. We thank the CEB (Communauté Electrique du Bénin), CIE (Compagnie 612 Ivoirienne d'Electricité), and AGETEER (Agence d'Execution des Travaux Eau et Equipement 613 Rural) for giving us the required authorizations for data publication. We thank the World Bank 614 for funding the first and third case studies. The second field study that we presented was fully 
615 funded by Electricité De France (EDF). We thank EDF as well for funding this project in 616 collaboration with the CNRS (Centre National pour la Recherche Scientifique). The resistivity 617 and self-potential measurements of the three case studies were collected by Fugro France. The 618 current density estimation performed in the last case study was carried out by a home-made 619 routine implemented by FUGRO France. We thank the two referees and the Editor for their 620 useful comments.

621 


\section{References}

623

624

625

626

627

628

630

631

632

633

634

635

636

637

638

639

640

641

642

643

644

645

646

Abdulsamad, F., Revil, A., Soueid Ahmed, A., Coperey, A., Karaoulis, M., Nicaise, S., Peyras, L., 2019. Induced polarization tomography applied to the detection and the monitoring of leaks in embankments. Engineering Geology 254, 89-101. https://doi.org/10.1016/j.enggeo.2019.04.001

Aina, A., Olorunfemi, M.O., Ojo, J.S., 1996. An integration of aeromagnetic and electrical resistivity methods in dam site investigation. Geophysics 61, 349-356.

Al-Saigh, N.H., Mohammed, Z.S., Dahham, M.S., 1994. Detection of water leakage from dams by self-potential method. Engineering Geology 37, 115-121. https://doi.org/10.1016/0013-7952(94)90046-9

Antoine, R., Fauchard, C., Fargier, Y., Durand, E., 2015. Detection of leakage areas in an earth embankment from GPR measurements and permeability logging. International Journal of Geophysics, vol. 2015.

Bolève, A., Vandemeulebrouck, J., Grangeon, J., 2012. Dyke leakage localization and hydraulic permeability estimation through self-potential and hydro-acoustic measurements: Selfpotential 'abacus' diagram for hydraulic permeability estimation and uncertainty computation. Journal of Applied Geophysics 86, 17-28.

Bonelli, S., 2013. Erosion in geomechanics applied to dams and levees. Wiley Online Library.

Cho, I.-K., Yeom, J.-Y., 2007. Crossline resistivity tomography for the delineation of anomalous seepage pathways in an embankment dam. Geophysics 72, G31-G38.

Daily, W., Ramirez, A., Binley, A., LeBrecque, D., 2004. Electrical resistance tomography. The Leading Edge 23, 438-442.

Darcy, H.P.G., 1856. Les Fontaines publiques de la ville de Dijon. Exposition et application des principes à suivre et des formules à employer dans les questions de distribution d'eau, etc. V. Dalamont. 
647 Di Prinzio, M., Bittelli, M., Castellarin, A., Pisa, P.R., 2010. Application of GPR to the monitoring of river embankments. Journal of Applied Geophysics 71, 53-61.

649 Edwards, L., 1977. A modified pseudosection for resistivity and IP. Geophysics 42, 1020-1036.

650 Ferdos, F., Dargahi, B., Solari, L., 2016. Mechanism of suffusion erosion phenomenon in $651 \quad$ Porous Media. J Geol Geosci 2: 001-018.

652 Günther, T., Rücker, C., Spitzer, K., 2006. Three-dimensional modelling and inversion of DC 653 resistivity data incorporating topography-II. Inversion. Geophysical Journal International 166, 506-517.

Gutiérrez, F., Desir, G., Gutiérrez, M., 2003. Causes of the catastrophic failure of an earth dam built on gypsiferous alluvium and dispersive clays (Altorricón, Huesca Province, NE Spain). Environmental Geology 43, 842-851.

Haario, H., Laine, M., Lehtinen, M., Saksman, E., Tamminen, J., 2004. Markov chain Monte Carlo methods for high dimensional inversion in remote sensing. Journal of the Royal Statistical Society: series B (statistical methodology) 66, 591-607.

Haario, H., Laine, M., Mira, A., Saksman, E., 2006. DRAM: efficient adaptive MCMC. Statistics and computing 16, 339-354.

Hastings, W.K., 1970. Monte Carlo sampling methods using Markov chains and their 664 applications. Biometrika, 57, 1, 1970, 97-109, https://doi.org/10.1093/biomet/57.1.97 Physics 69, 943-952.

Howard, A.D., McLane, C.F., 1988. Erosion of cohesionless sediment by groundwater seepage. Water Resources Research 24, 1659-1674.

Hui, L., Haitao, M., 2011. Application of ground penetrating radar in dam body detection. Procedia Engineering 26, 1820-1826. 
671 Ikard, S.J., Revil, A., Jardani, A., Woodruff, W.F., Parekh, M., Mooney, M., 2012. Saline pulse test monitoring with the self-potential method to nonintrusively determine the velocity of the pore water in leaking areas of earth dams and embankments, Water Resour.Res.,48, W04201, https://doi.org/10.1029/2010WR010247.

James, L.B., 1968. Failure of the Baldwin Hills Reservoir in Los Angeles, California. Geological Society of America. Engineering Geology Case Histories 6, 1-11.

Jardani, A., Dupont, J.-P., Revil, A., 2006. Self-potential signals associated with preferential 678 groundwater flow pathways in sinkholes. J. Geophys. Res., 111, B09204, https://doi.org/10.1029/2005JB004231.

Jardani, A., Dupont, J.-P., Revil, A., Massei, N., Fournier, M., Laignel, B., 2012. Geostatistical 681 682 inverse modeling of the transmissivity field of a heterogeneous alluvial aquifer under tidal influence. Journal of hydrology 472, 287-300.

Jougnot, D., Mendieta, A., Leroy, P., Maineult, A., 2019. Exploring the effect of the pore size distribution on the streaming potential generation in saturated porous media, insight from pore network simulations. Journal of Geophysical Research: Solid Earth, 124, 5315- 5335. https://doi.org/10.1029/2018JB017240

Li, X., Fan, L., Huang, H., Hao, J., Li, M., 2018. Application of Ground Penetrating Radar in Leakage Detection of Concrete Face Rockfill Dam, in: IOP Conference Series: Earth and Environmental Science. IOP Publishing, p. 022044.

Loke, M.H., 2004. Tutorial: 2-D and 3-D electrical imaging surveys.

691 Loke, M.H., Barker, R.D., 1996. Rapid least-squares inversion of apparent resistivity pseudosections by a quasi-Newton method 1. Geophysical prospecting 44, 131-152.

693 Metropolis, N., Rosenbluth, A.W., Rosenbluth, M.N., Teller, A.H., Teller, E., 1953. Equation 694 695 of state calculations by fast computing machines. The journal of chemical physics 21 , 1087-1092. 
Mosegaard, K., Tarantola, A., 1995. Monte Carlo sampling of solutions to inverse problems. Journal of Geophysical Research: Solid Earth 100, 12431-12447.

Panthulu, T.V., Krishnaiah, C., Shirke, J.M., 2001. Detection of seepage paths in earth dams using self-potential and electrical resistivity methods. Engineering Geology 59, 281295. https://doi.org/10.1016/S0013-7952(00)00082-X

Revil, A., Jardani, A., 2013. The self-potential method: Theory and applications in environmental geosciences. Cambridge University Press.

Revil, A., Karaoulis, M., Johnson, T., Kemna, A., 2012. Some low-frequency electrical methods for subsurface characterization and monitoring in hydrogeology. Hydrogeology Journal 20, 617-658.

Richards, L.A., 1931. Capillary conduction of liquids through porous mediums. Physics 1, 318333.

Sambridge, M., Mosegaard, K., 2002. Monte Carlo methods in geophysical inverse problems. Reviews of Geophysics 40, 3-1-3-29.

Sheffer, M.R., Oldenburg, D.W., 2007. Three-dimensional modelling of streaming potential. Geophysical Journal International 169, 839-848.

Sjödahl, P., Dahlin, T., Johansson, S., Loke, M.H., 2008. Resistivity monitoring for leakage and internal erosion detection at Hällby embankment dam. Journal of Applied Geophysics 65, 155-164.

Soueid Ahmed, A., Jardani, A., Revil, A., Dupont, J.P., 2013. SP2DINV: A 2D forward and inverse code for streaming potential problems. Computers \& Geosciences 59, 9-16. https://doi.org/10.1016/j.cageo.2013.05.008

Soueid Ahmed, A., Revil, A., Byrdina, S., Coperey, A., Gailler, L., Grobbe, N., Viveiros, F., Silva, C., Jougnot, D., Ghorbani, A., 2018. 3D electrical conductivity tomography of volcanoes. Journal of Volcanology and Geothermal Research 356, 243-263. 
721 Soueid Ahmed, A., Revil, A., Steck, B., Vergniault, C., Jardani, A., Vinceslas, G., 2019. Selfpotential signals associated with localized leaks in embankment dams and dikes. Engineering Geology,253, 229-239.

724 Sternberg, B.K., 1979. Electrical resistivity structure of the crust in the southern extension of the Canadian Shield-Layered Earth Models. Journal of Geophysical Research: Solid Earth 84, 212-228.

Tikhonov, A.N., 1943. On the stability of inverse problems, in: Dokl. Akad. Nauk SSSR. pp. 728 195-198.

729 Xu, X., Zeng, Q., Li, D., Wu, J., Wu, X., Shen, J., 2010. GPR detection of several common subsurface voids inside dikes and dams. Engineering Geology 111, 31-42. 
733 Table 1. Synthetic test: Physical properties of the different components of the dam.

\begin{tabular}{llllll}
\hline & Water & Foundation & $\begin{array}{l}\text { Seepage flow } \\
\text { path }\end{array}$ & Core & Structure \\
\hline Permeability $\left(\mathrm{m}^{2}\right)$ & 0.1 & $10^{-16}$ & $10^{-10}$ & $10^{-18}$ & $10^{-15}$ \\
Resistivity (Ohm m) & 600 & 1,000 & 300 & 100 & 2,000 \\
\hline
\end{tabular}

Table 2. Field study 1: Physical properties of the different components of the dam.

\begin{tabular}{llllll}
\hline & Water & Foundation & $\begin{array}{l}\text { Seepage flow } \\
\text { path }\end{array}$ & Core & Structure \\
\hline Permeability $\left(\mathrm{m}^{2}\right)$ & 0.1 & $10^{-18}$ & $510^{-9}$ & $10^{-20}$ & $10^{-17}$ \\
Resistivity (Ohm m) & 100 & 1,000 & 400 & 400 & 800 \\
\hline
\end{tabular}

Table 3. Field study 2: Physical properties of the different components of the dam.

\begin{tabular}{llllll}
\hline & Water & Foundation & $\begin{array}{l}\text { Seepage flow } \\
\text { path }\end{array}$ & Core & Structure \\
\hline Permeability $\left(\mathrm{m}^{2}\right)$ & 0.1 & $10^{-18}$ & $2.510^{-9}$ & $10^{-17}$ & $10^{-15}$ \\
Resistivity (Ohm m) & 130 & 1,000 & 100 & 100 & 2,000 \\
\hline
\end{tabular}

Table 4. Field study 3: physical properties of the different components of the dam.

\begin{tabular}{|c|c|c|c|c|c|c|}
\hline & water & dam & $\begin{array}{l}\text { Lateritic } \\
\text { material }\end{array}$ & $\begin{array}{l}\text { Lateritic } \\
\text { clay }\end{array}$ & $\begin{array}{l}\text { Doleritic } \\
\text { sand }\end{array}$ & $\begin{array}{l}\text { Fresh } \\
\text { Dolerite }\end{array}$ \\
\hline Permeability $\left(\mathrm{m}^{2}\right)$ & 0.1 & $10^{-16}$ & $10^{-14}$ & $1.410^{-14}$ & $\begin{array}{c}910^{-13}- \\
910^{-15}\end{array}$ & $\begin{array}{c}910^{-16}- \\
910^{-17}\end{array}$ \\
\hline Resistivity (Ohm m) & 400 & 600 & $\begin{array}{c}1,000- \\
1,500\end{array}$ & $200-600$ & $100-200$ & $\begin{array}{c}2,000- \\
4,500\end{array}$ \\
\hline
\end{tabular}




\section{Synthetic test}
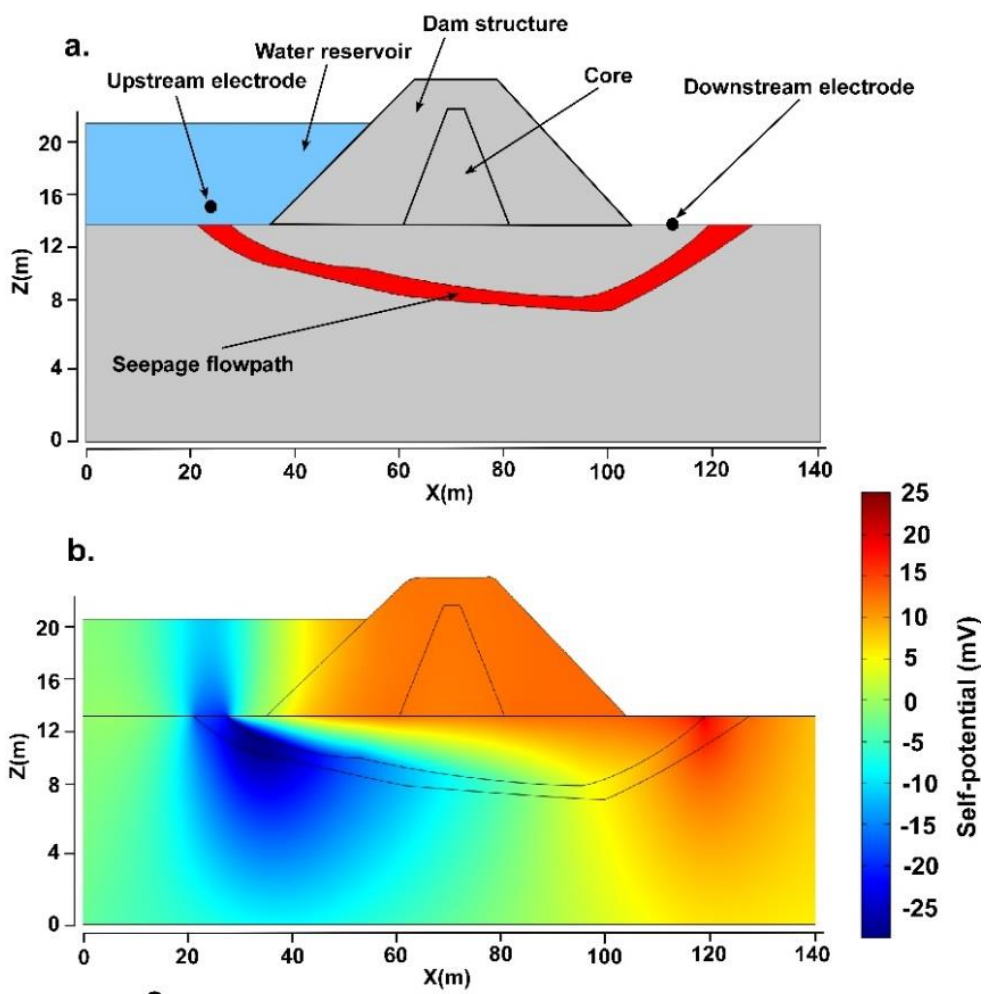

c.

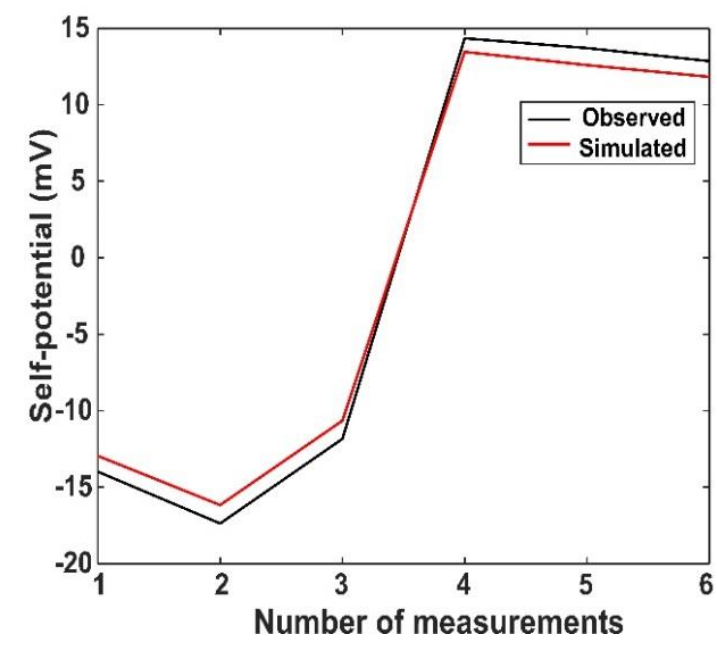

743 Figure 1. Synthetic test. a. Geometry of the synthetic dam. The measurements are collected on

744 two electrodes, one located upstream and the other downstream. The hypothetical seepage flow

745 path is highlighted in red. b. The true self-potential distribution observed across the dam. The

746 reference electrode is placed far away from the region of interest. Its potential is negligible. A

747 positive anomaly can be observed downstream while a negative one is visible upstream at the

748 vicinity of the seepage area. c. Observed and computed self-potential signals. The self-potential

749 signal generated using the best permeability estimate, reproduces well the exact self-potential 750 signal. 

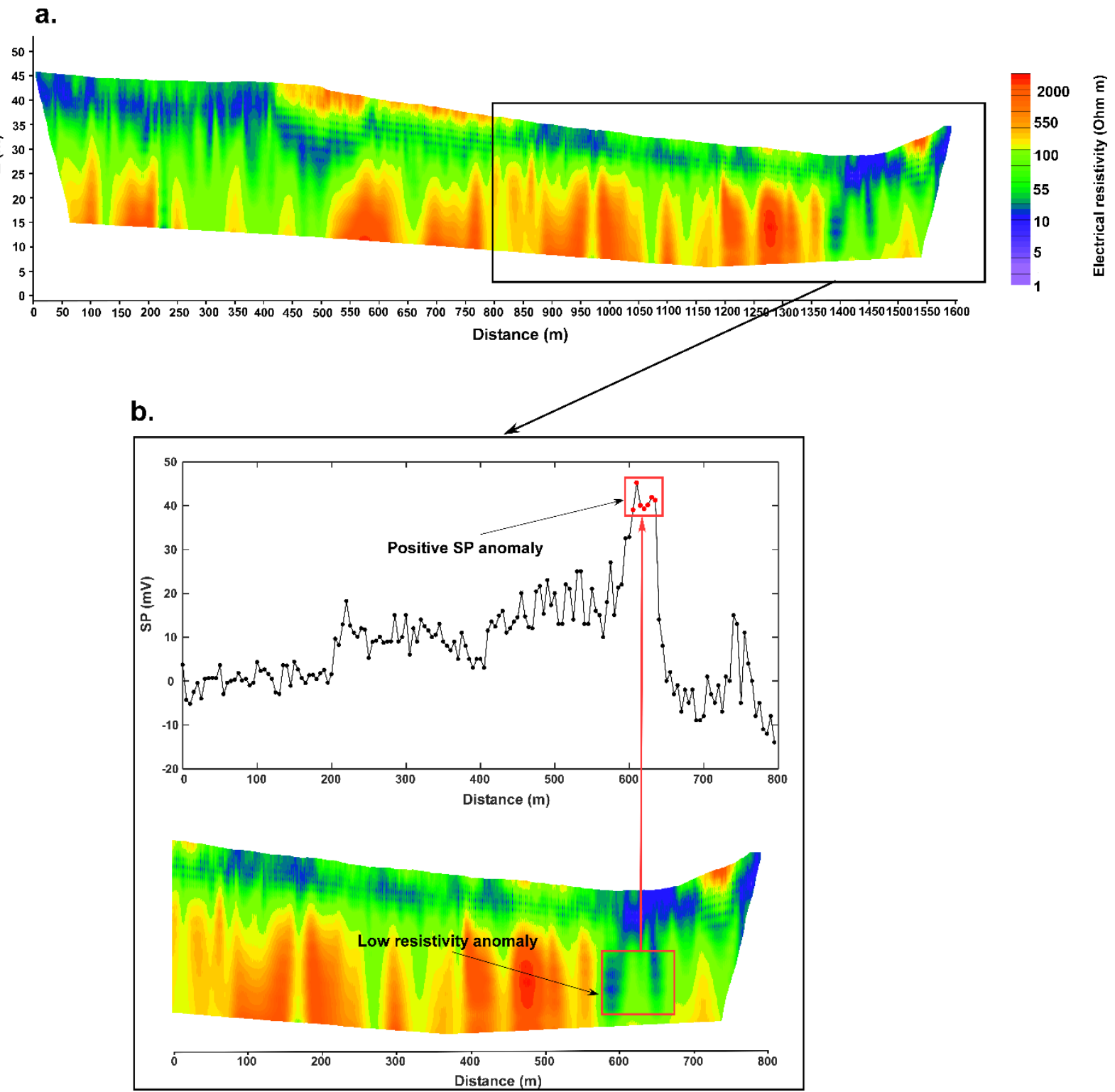

753 Figure 2. Field study 1: Geoelectrical measurements collected on the left bank dike.

754 a. Downstream electrical resistivity profile. The foundation of the dam is located in a globally 755 highly resistive gneiss rock except between the abscissas $1440 \mathrm{~m}$ and 1490m where conductive anomalies are observed. The self-potential measurements show a peak at the same location. $\mathbf{b}$. Zoom on the suspected seepage area. The conductive resistivity anomalies coincide with the location of a +30 to $+35 \mathrm{mV}$ self-potential anomaly (red points on the curve) that is reflective of the presence of a preferential flow path in the dam structure. The resistivity profile is 1180 $\mathrm{m}$ long but we only show the part of the profile that contains the low resistivity anomaly associated with the seepage area. Some shallow low resistivity anomalies associated with the conductive nature of terrain are observed as well. 


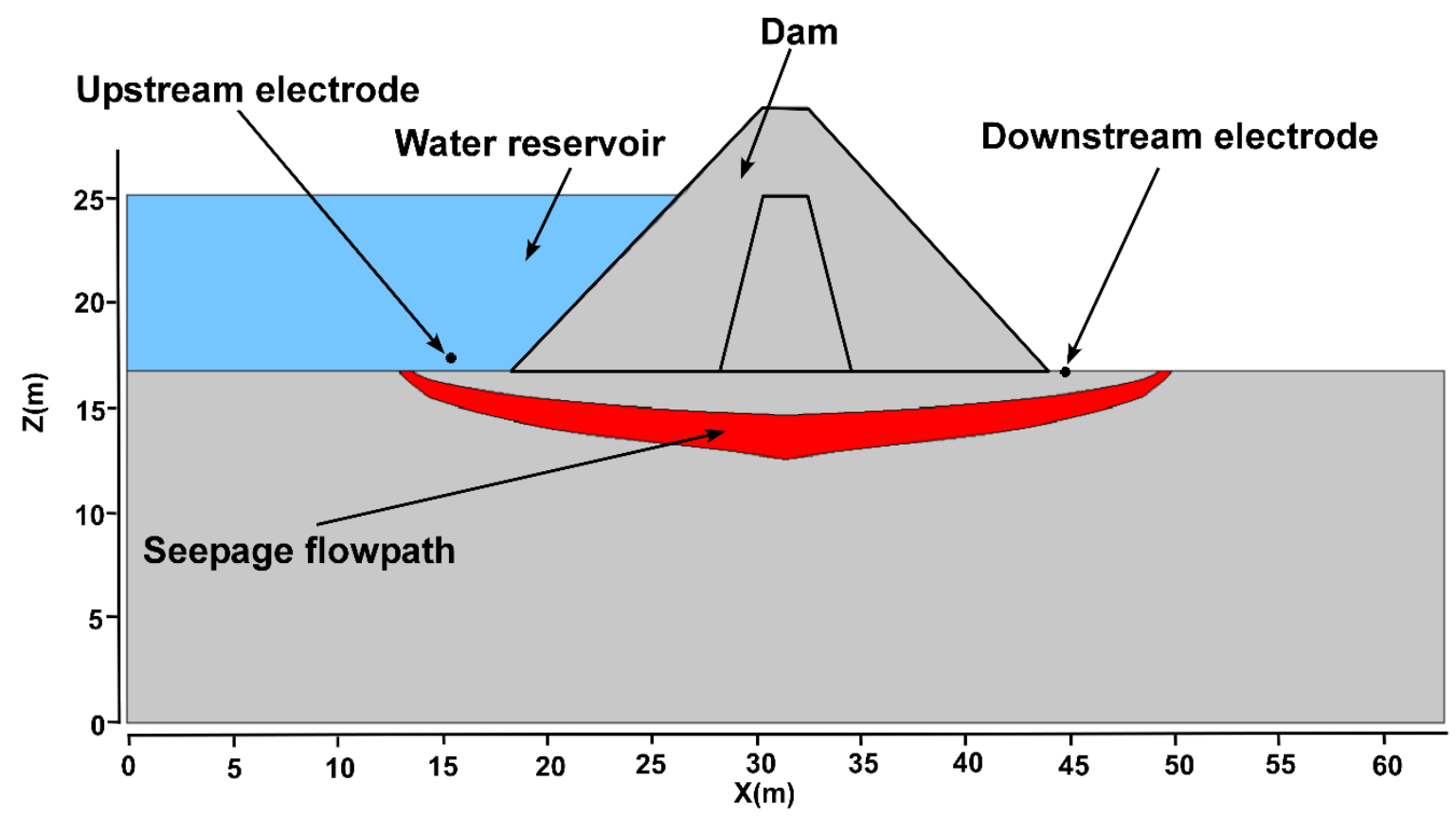

767 Figure 3. Field study 1: Simulation domain geometry. The different components of the dam 768 that are modeled are represented. Two electrodes, one located at $1 \mathrm{~m}$ from the bottom of the 769 reservoir and the other located upstream at $2.5 \mathrm{~m}$ from the bottom of the dam, are used to 770 measure the self-potential signals.

771 


\section{Field study 1}
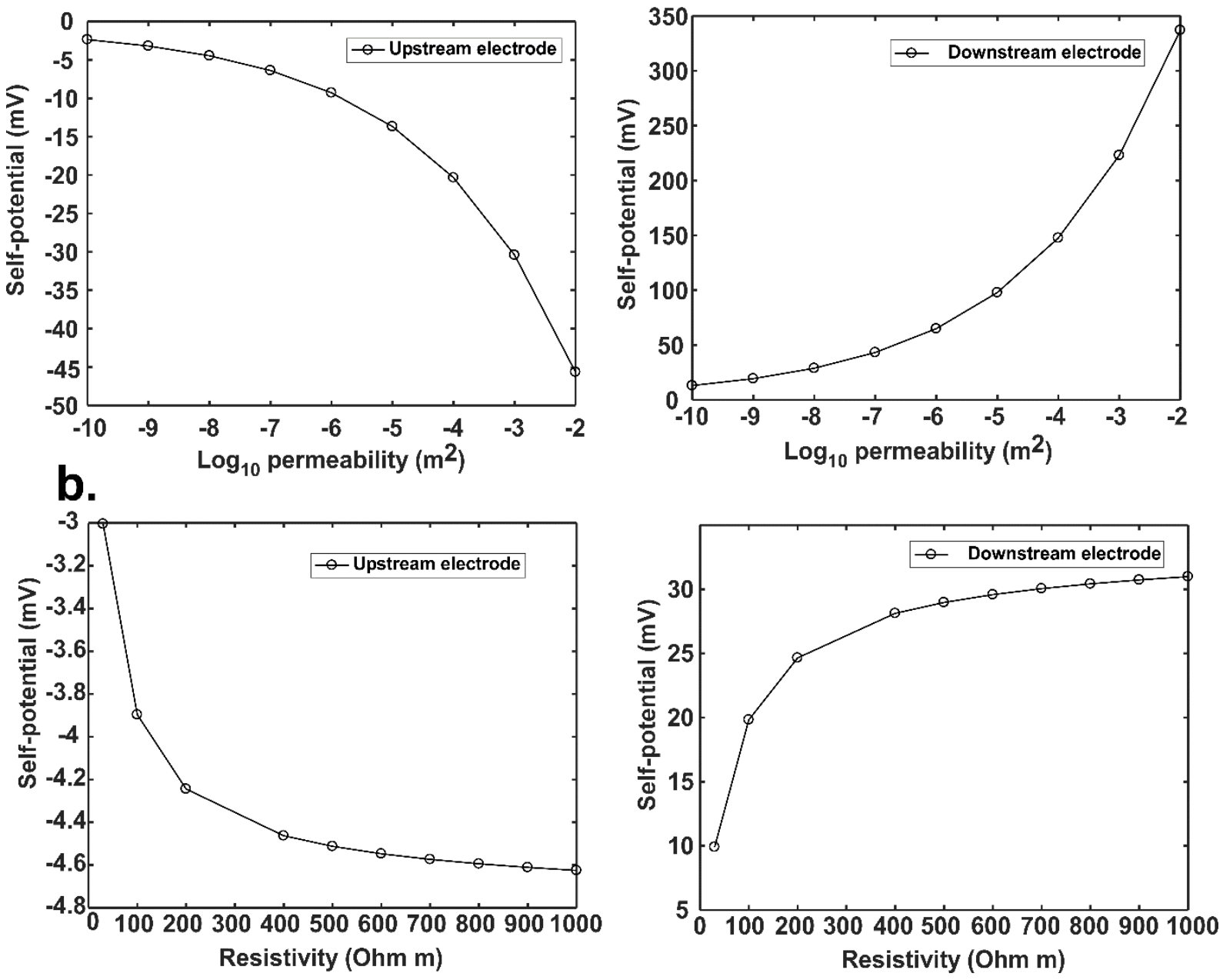

775 Figure 4. Field study 1: Sensitivity analysis on the seepage flow path properties. a. Permeability of the seepage flow path. b. Resistivity of the seepage flow path. The permeability and the resistivity of the seepage flow path are varied to find the orders-of-magnitude of these properties that enable simulation of the observed self-potential anomalies. A permeability comprised between $10^{-9}$ and $10^{-8} \mathrm{~m}^{2}$ and a resistivity of around $400 \mathrm{Ohm}$ m approximates the observed self-potential amplitudes downstream and upstream. 


\section{a. $\quad$ Field study 1}
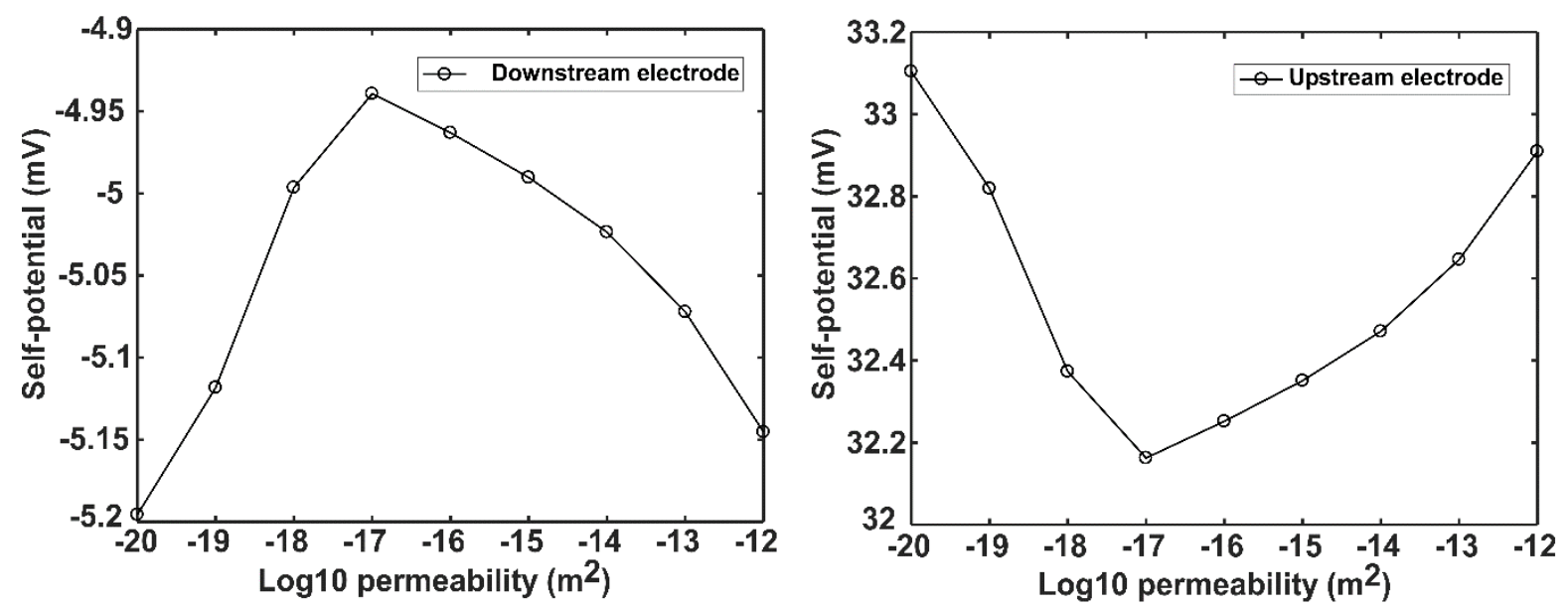

b.
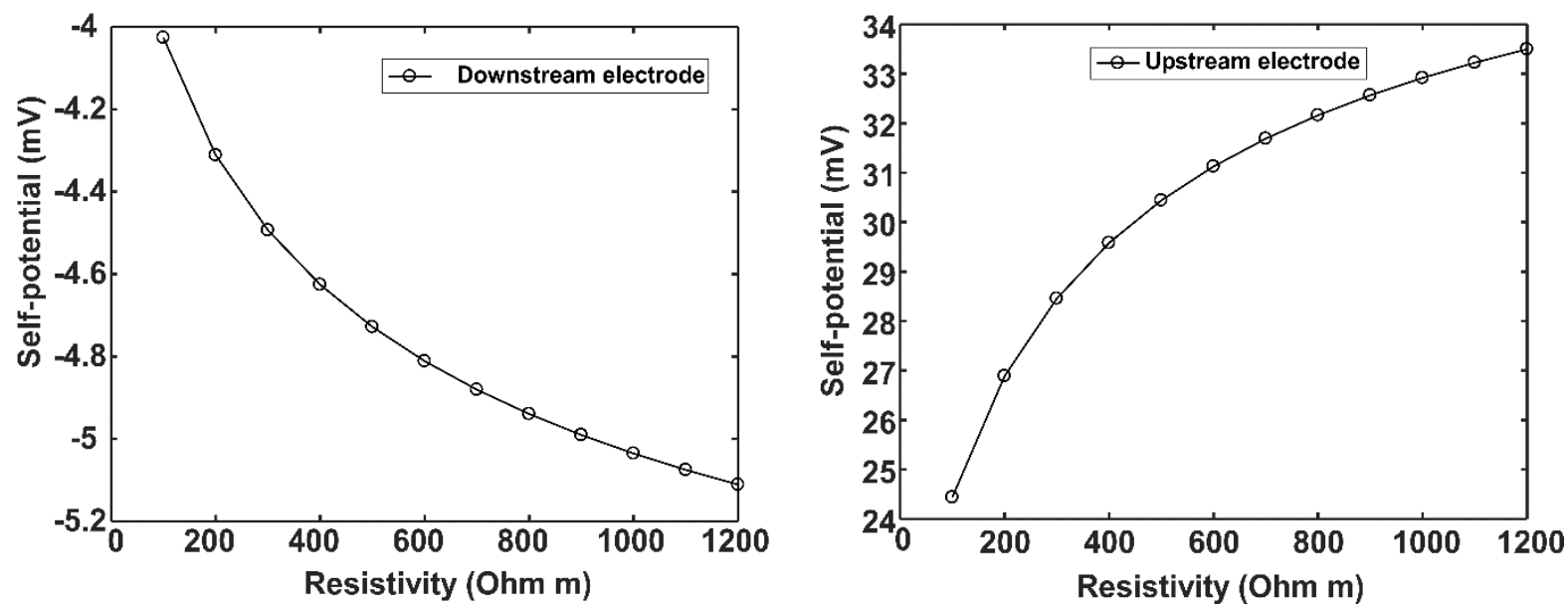

787 Figure 5. Field study 1: Sensitivity analysis on the dam structure properties. a. Permeability of the dam structure. The permeability of the structure has a weak influence on the observed selfpotential amplitudes. The permeability of the structure has a weak influence on the observed self-potential, which change roughly 0.2 to $0.8 \mathrm{mV}$ over 10 orders of magnitude of permeability. As one can see, varying the permeability of the dam structure only results in a very slight

792 variation of the self-potential signal. b. Resistivity of the dam structure. The self-potential signal 793 seems to not significantly vary with the resistivity of the structure unless for the low resistivity 794 environments. 
Field study 1
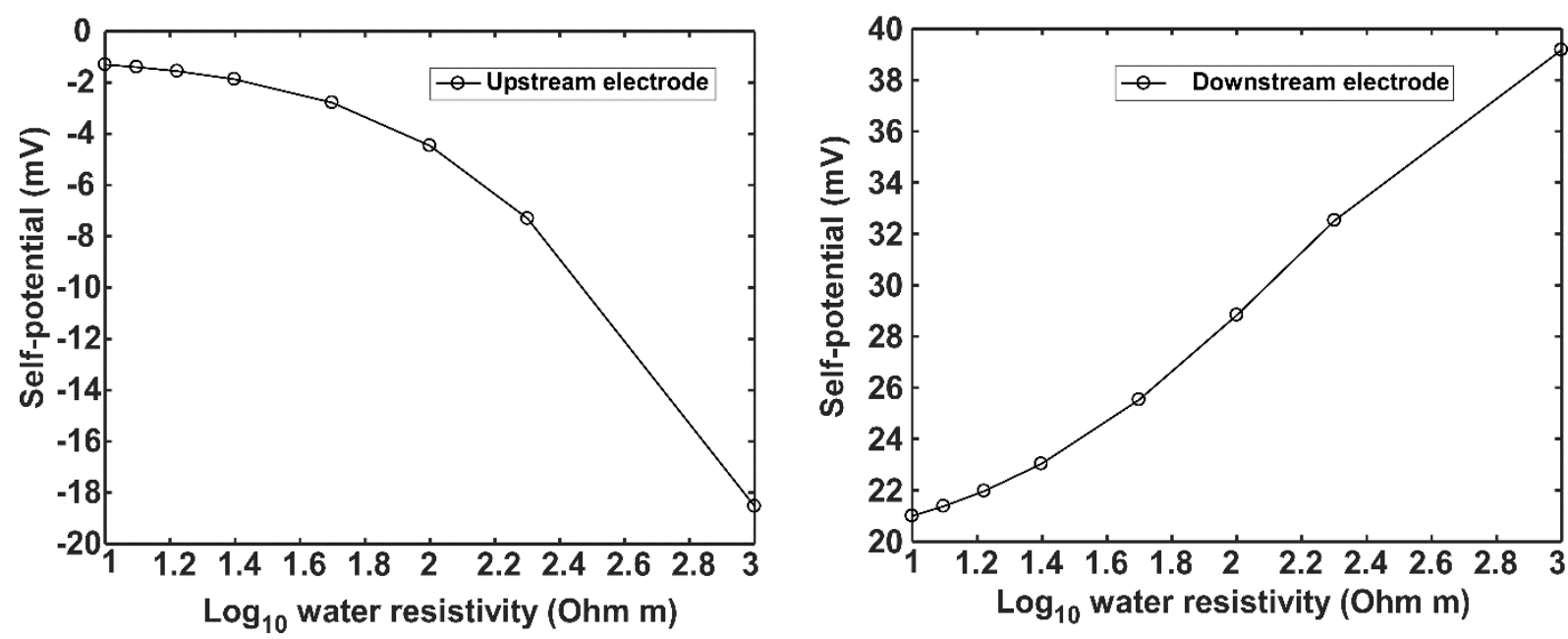

799

800 Figure 6. Field study 1: Sensitivity analysis on the resistivity of the water of the reservoir. The 801 observed self-potential magnitudes are retrieved with a resistivity ranging from 50 to $100 \mathrm{Ohm}$ $802 \mathrm{~m}$. This is in accordance with the measurement of the resistivity of the water on the field which 803 was found to be $50 \mathrm{Ohm} \mathrm{m}$.

804

805 

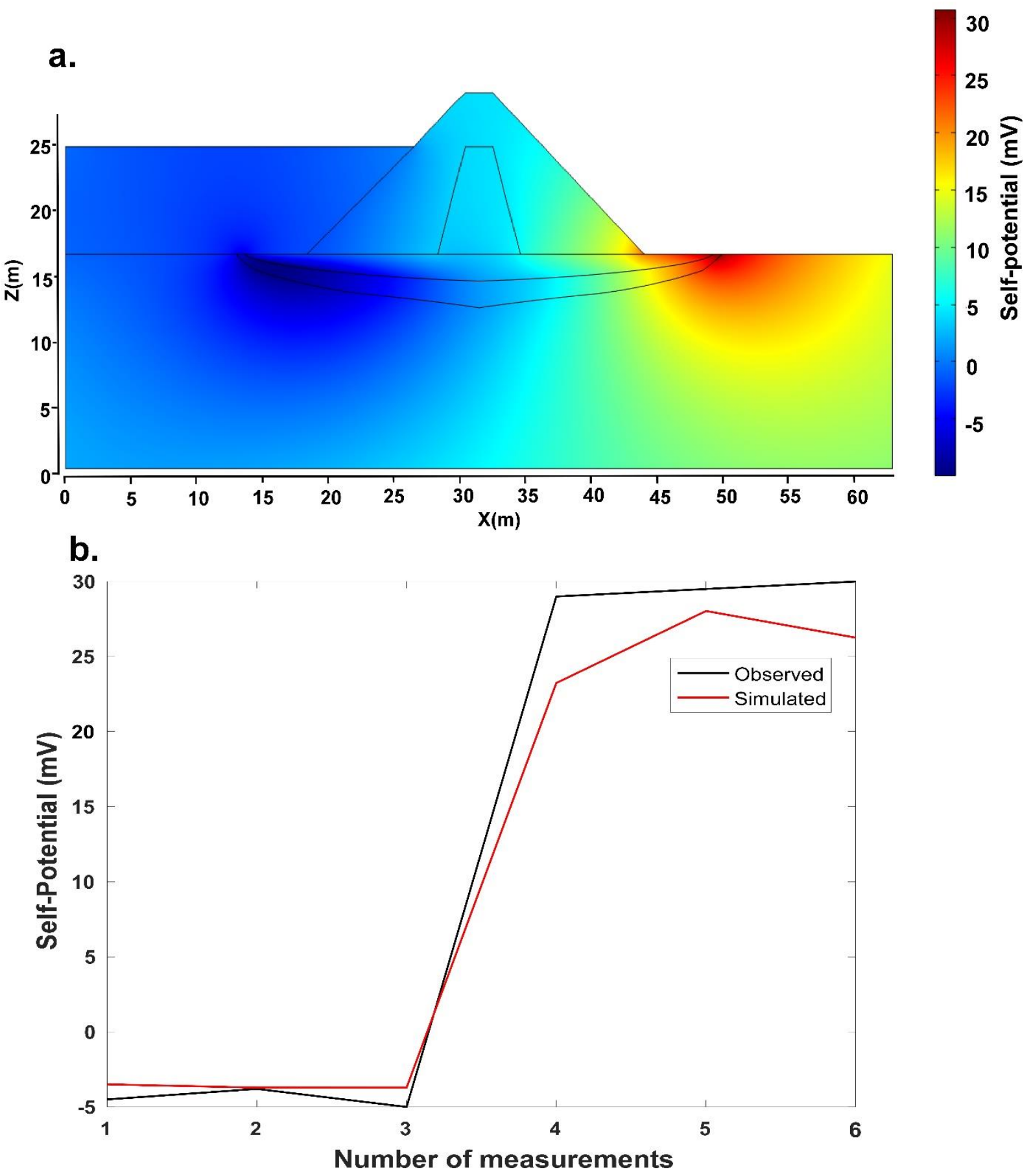

809 Figure 7. Field study 1: self-potential signal: a. Simulated self-potential distribution. b. 810 Observed against simulated self-potential signal. There is a very good match between the 811 observed and self-potential signal. The self-potential distribution clearly shows regions of 812 negative and positive self-potential anomalies at the ends of the preferential flow path. 


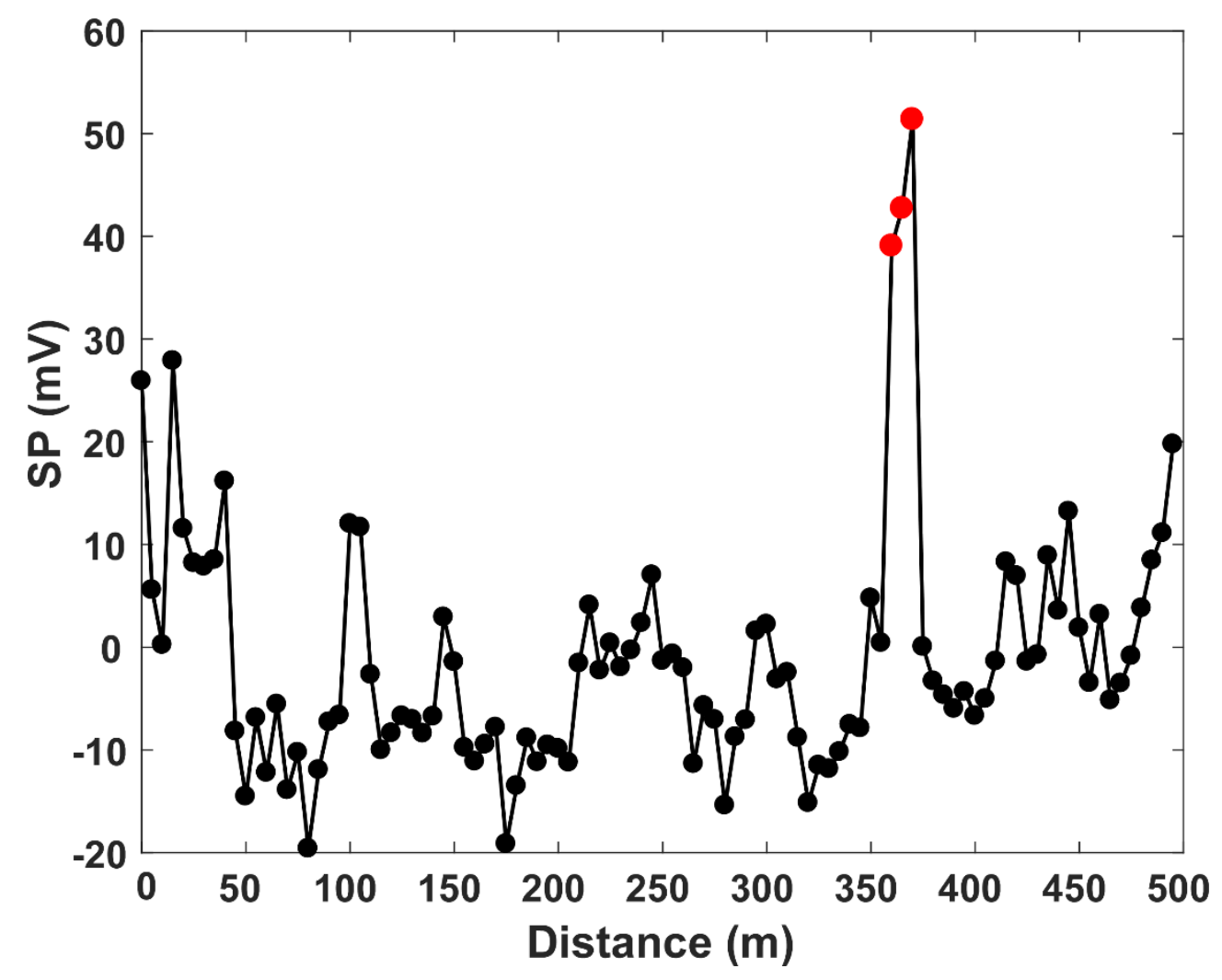

816

817 Figure 8. Field study 2: self-potential measurements collected on the right side of the dike. This 818 self-potential profile was measured on the bottom of the right bank in a region where water was 819 emerging. A positive anomaly with an amplitude of 40 to $50 \mathrm{mV}$ (represented by the red points) 820 is observed at the vicinity of this resurgence area. The self-potential electrodes have a $5 \mathrm{~m}$ 821 interval.

822 


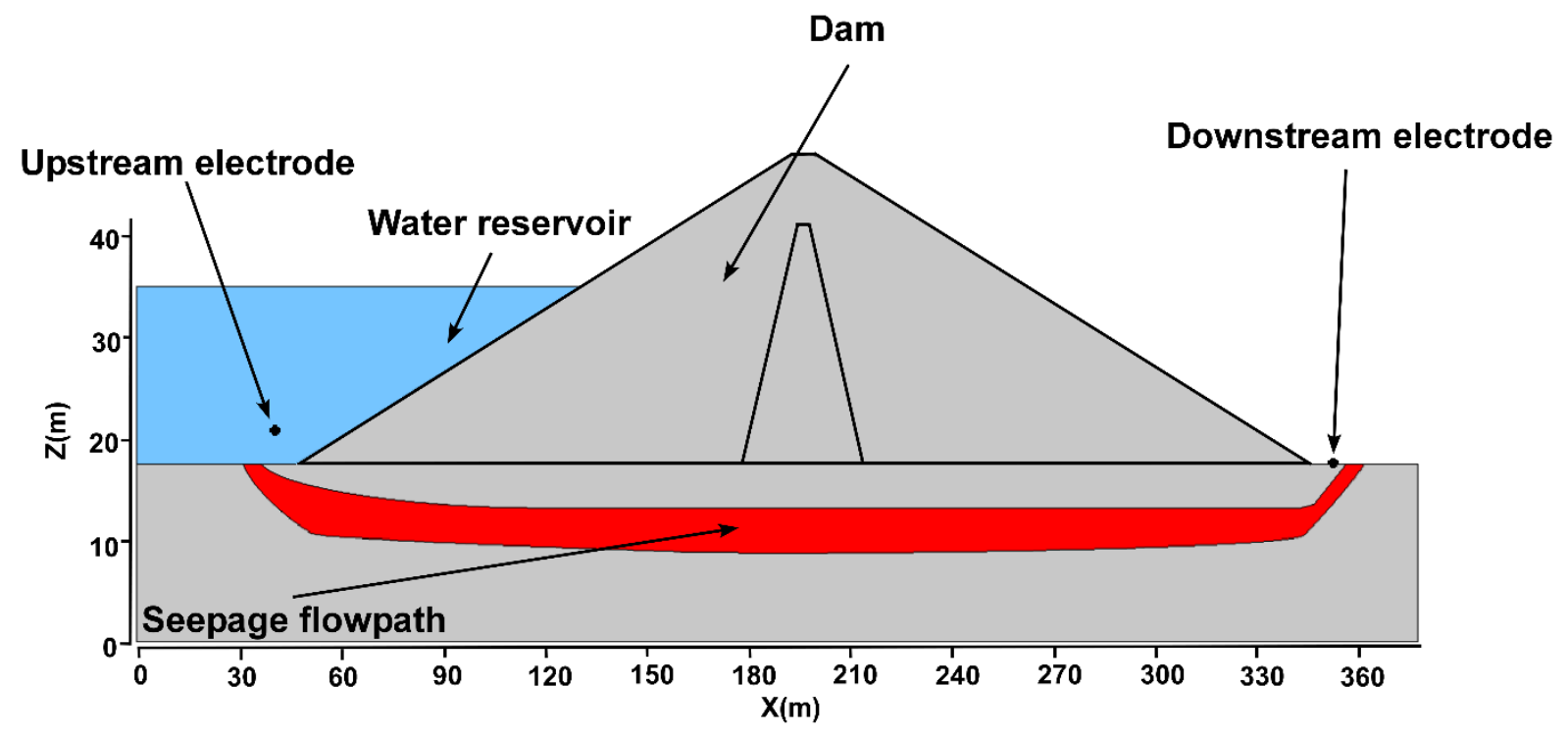

828

829 Figure 9. Simulation domain geometry for the field study 2. The different components of the 830 dam that are modelled are represented. The self-potential simulated signal is collected at an 831 electrode located at one $1 \mathrm{~m}$ from the bottom of the reservoir and Another electrode located 832 upstream at $2 \mathrm{~m}$ from the bottom of the dam.

833

834 
a.
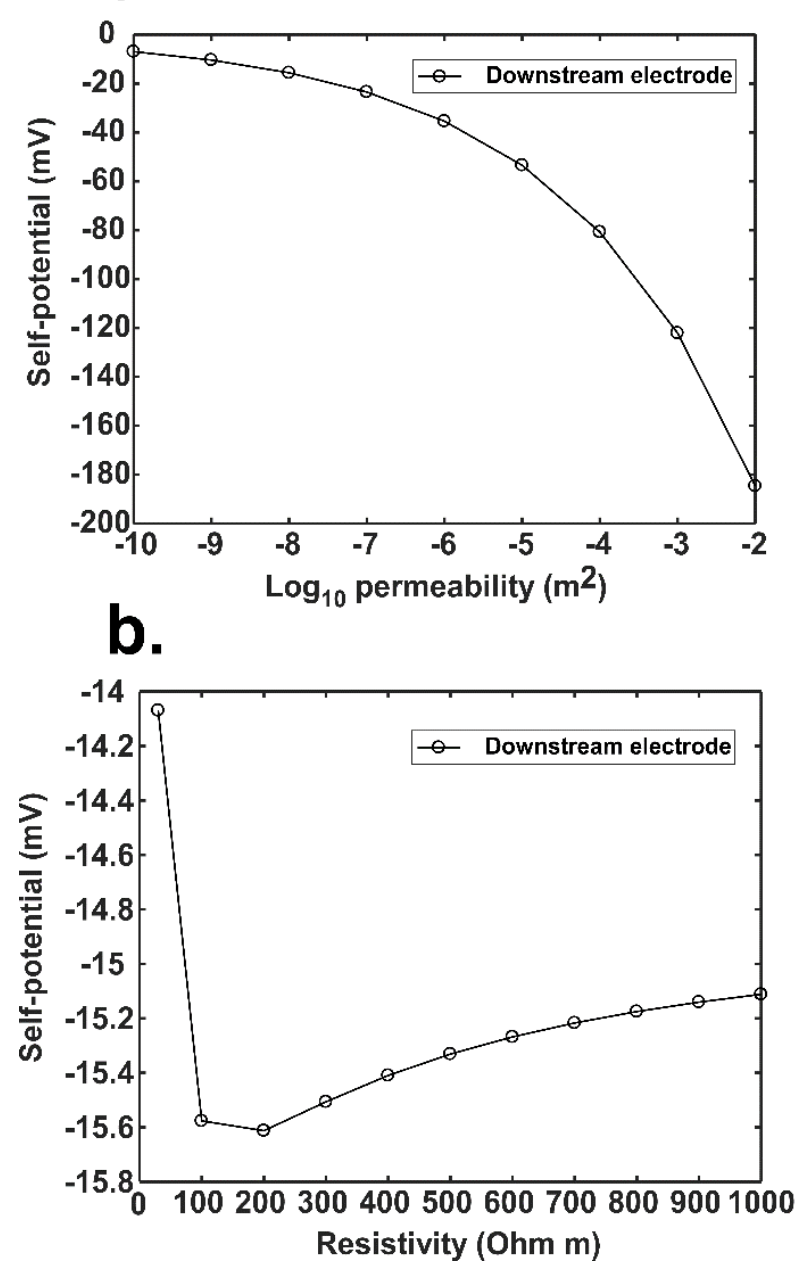

\section{Field study 2}
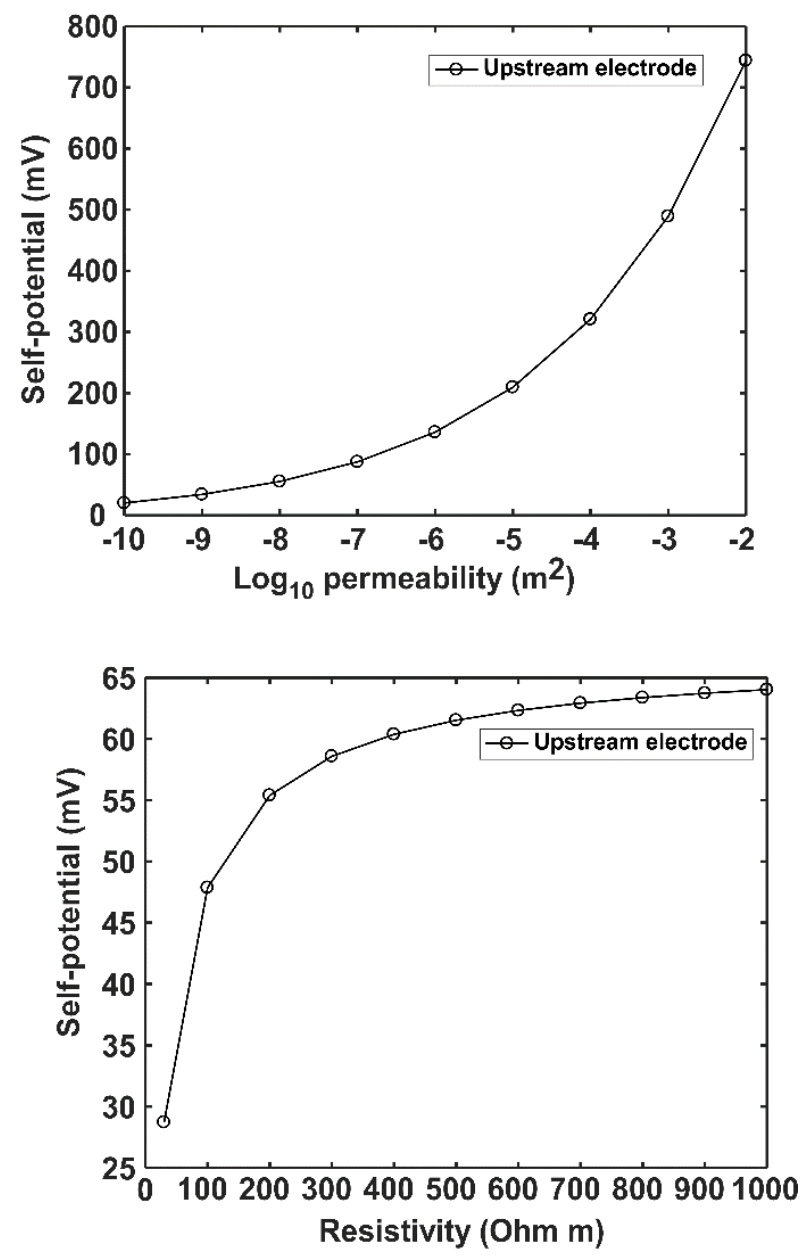

838 Figure 10. Field study 2: Sensitivity analysis on the seepage flow path properties. a.

839 Permeability of the seepage flow path. b. Resistivity of the seepage flow path. The permeability

840 and the resistivity of the seepage flow path are varied to find the orders-of-magnitude of these

841 properties that approximate the amplitude of observed self-potential anomalies. The sensitivity 842 analysis shows that the permeability (expressed in $\mathrm{m}^{2}$ ) is in the range $\left[10^{-9}, 10^{-8}\right]$. This range 843 will be used as a constraint will be used as constraints in the inversion process of estimating the 844 seepage flow path permeability. The resistivity of the seepage flow path that recovers the 845 observed self-potential observations (i.e., $-15 \mathrm{mV}$ upstream and $+50 \mathrm{mV}$ downstream) is 846 around 100-150 Ohm $\mathrm{m}$. 
a. Field study 2
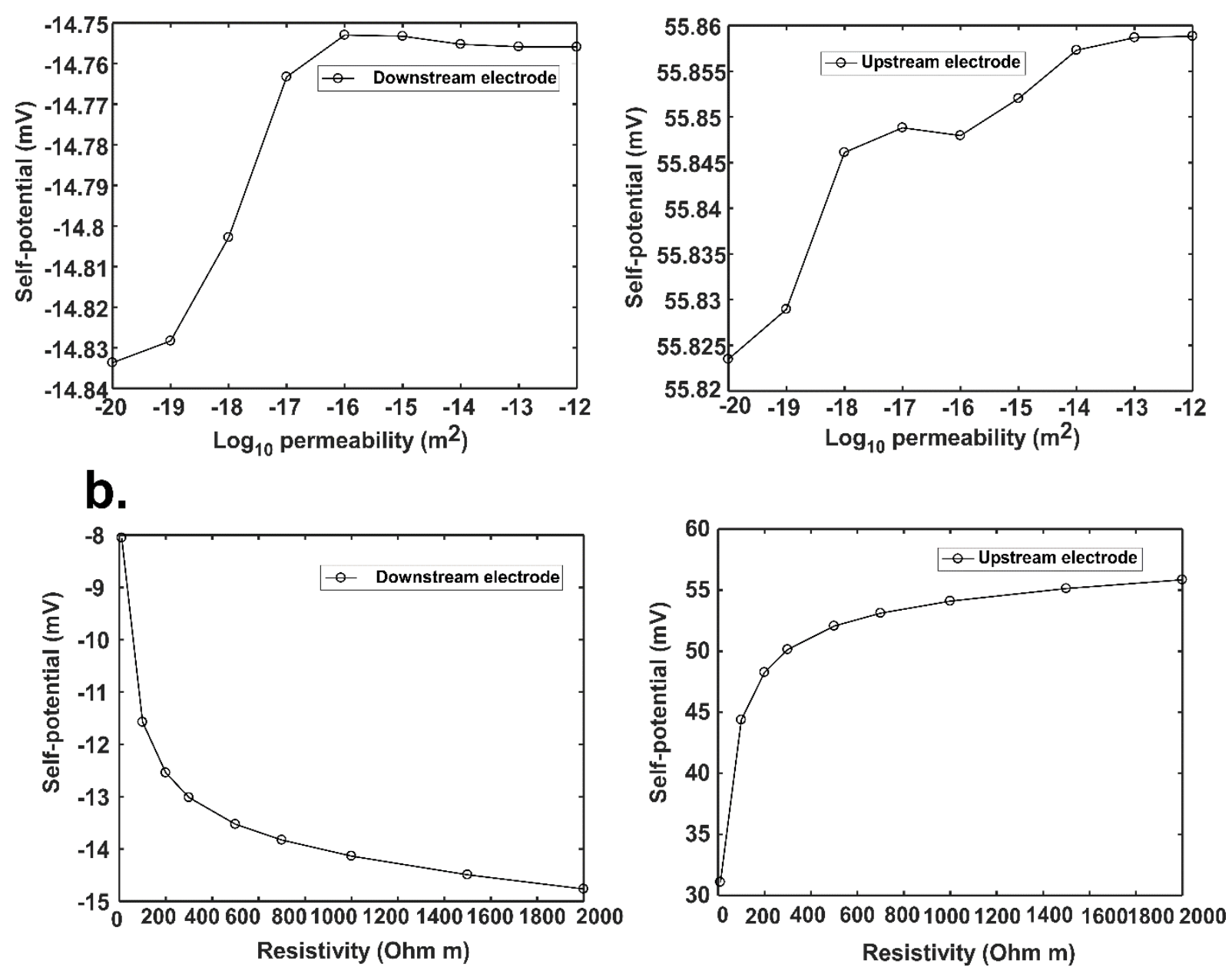

854 Figure 11. Field study 2: Sensitivity analysis on the dam structure properties. a. Permeability 855 of the dam structure. Despite the wide range of permeability used in this sensitivity analysis, 856 we notice that self-potential signal does not vary significantly, which suggests that the 857 permeability of the structure is not the main parameter that influence self-potential signal 858 generated on a dam. However, the resistivity of the structure appears to have a larger impact on 859 the self-potential signal especially when are working in conductive media. 
Field study 2
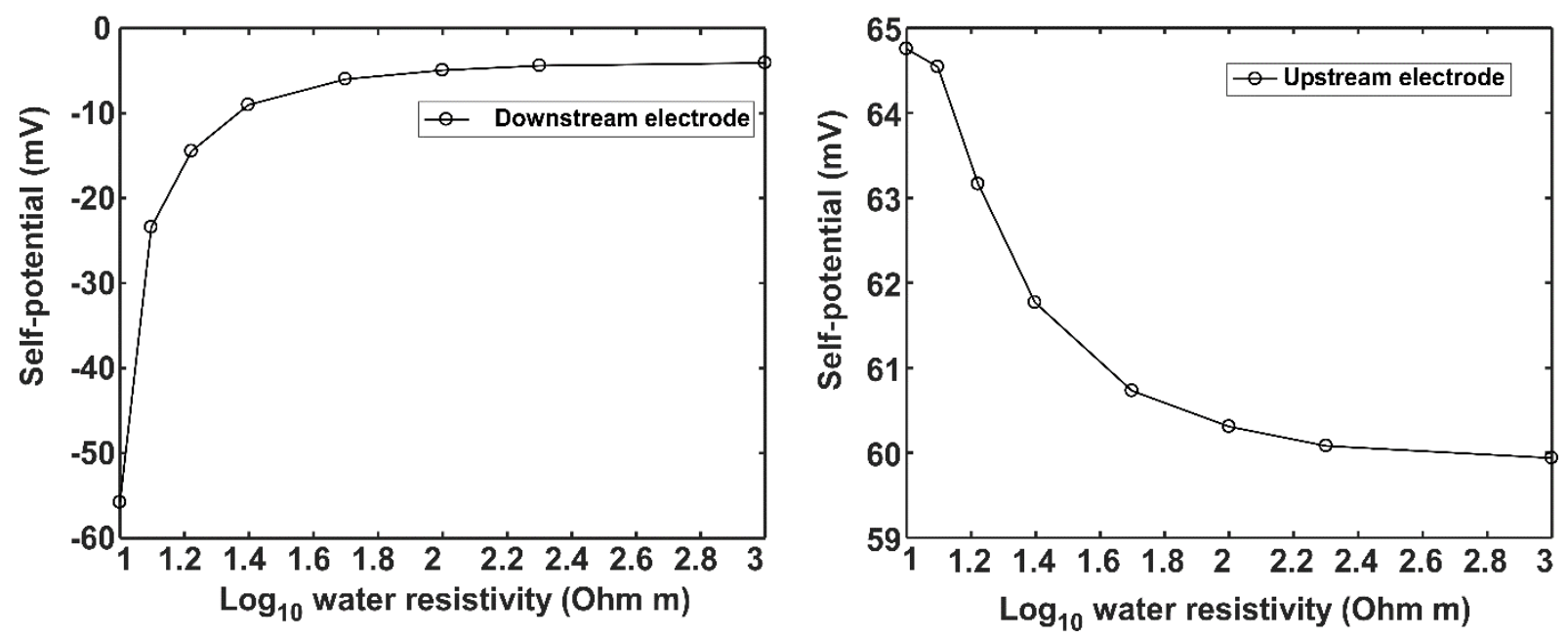

863

864

865 Figure 12. Field study 2: Sensitivity analysis on the resistivity of the water of the reservoir.

866 This sensitivity analysis is performed to check the correctness of the water resistivity 867 measurement that we performed on the field, which was $100 \mathrm{Ohm} \mathrm{m}$. Observing the figure 868 shows that the observed self-potential amplitudes are retrieved using resistivities ranging from 86912.5 to $100 \mathrm{Ohm} \mathrm{m}$.

870 


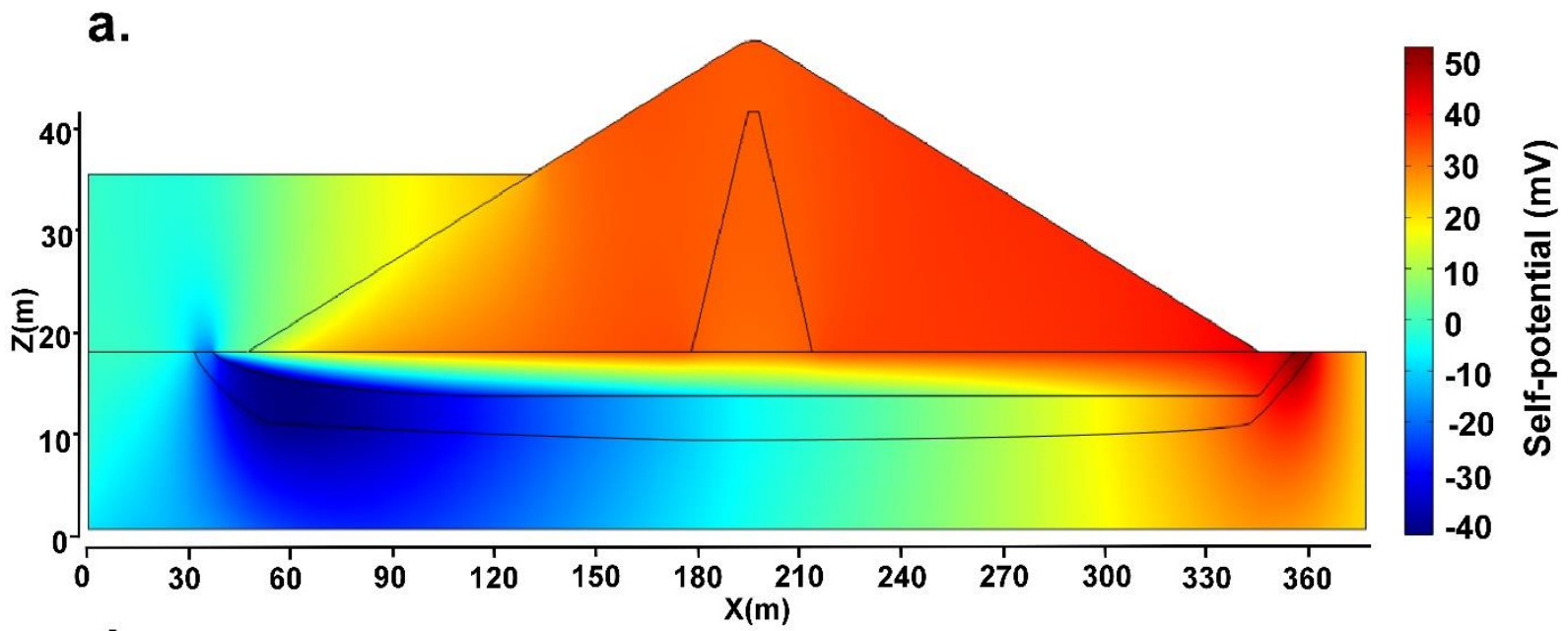

b.

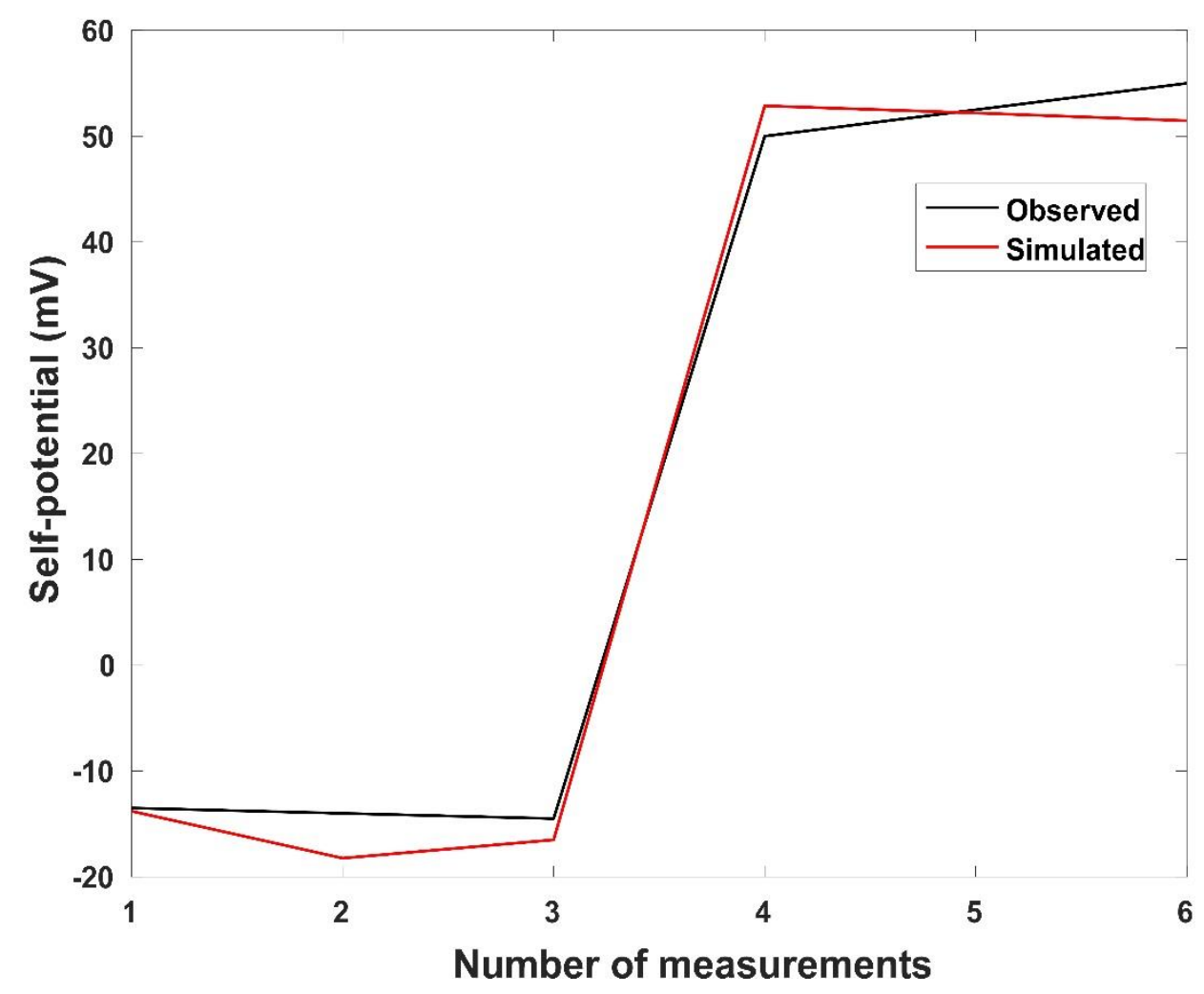

874 Figure 13. Field study 2: self-potential signal: a. Simulated self-potential distribution. b.

875 Observed against simulated self-potential signal. There is a very good match between the 876 observed and self-potential signal. The self-potential distribution clearly shows regions of 877 negative and positive self-potential anomalies at the ends of the preferential flow path. 


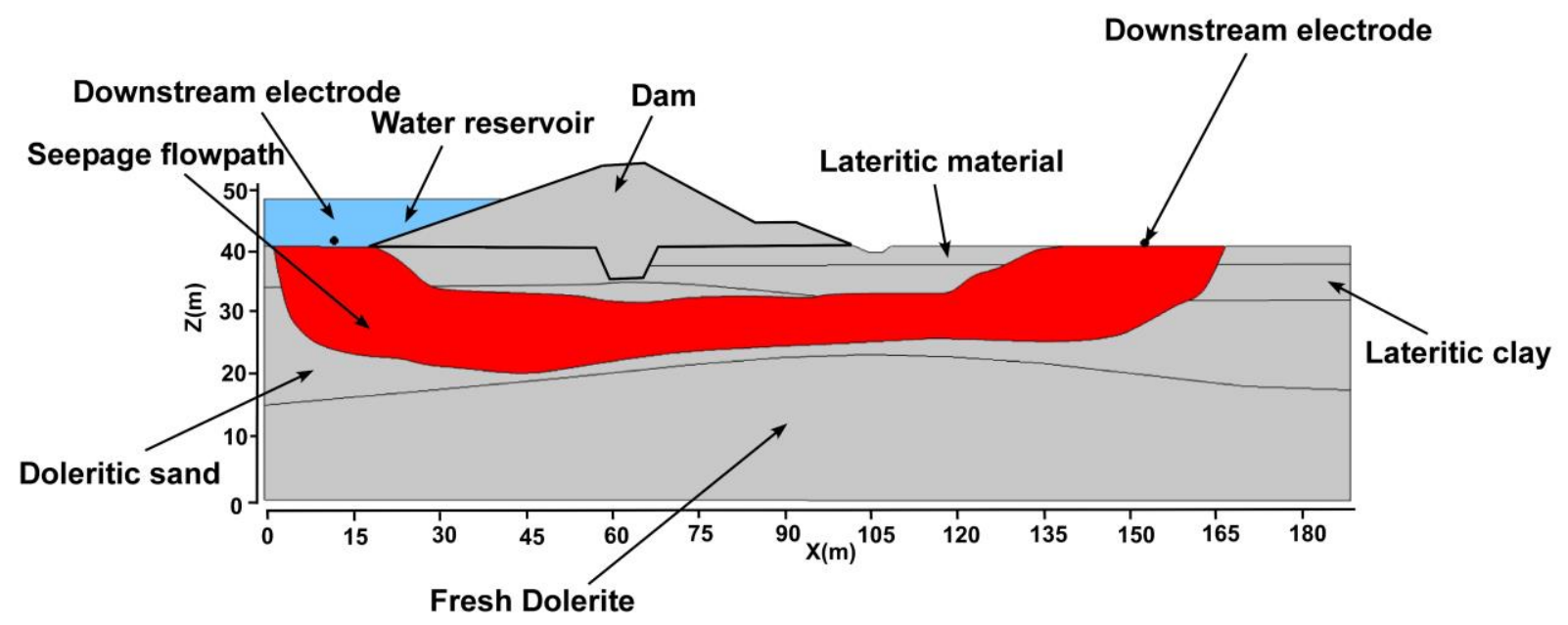

880

881 Figure 14. Sketch of the domain geometry for the field study 3: The different components of 882 the dam are modelled as well as the geological units of the site. The self-potential simulated 883 signal is collected at an electrode located at one $1 \mathrm{~m}$ from the bottom of the reservoir and another 884 electrode located upstream at ground surface. The seepage flow path geometry (Figure 15) has 885 been approximated using a linear inverse process, which depicts the source current density from 886 self-potential observations.

887

888 

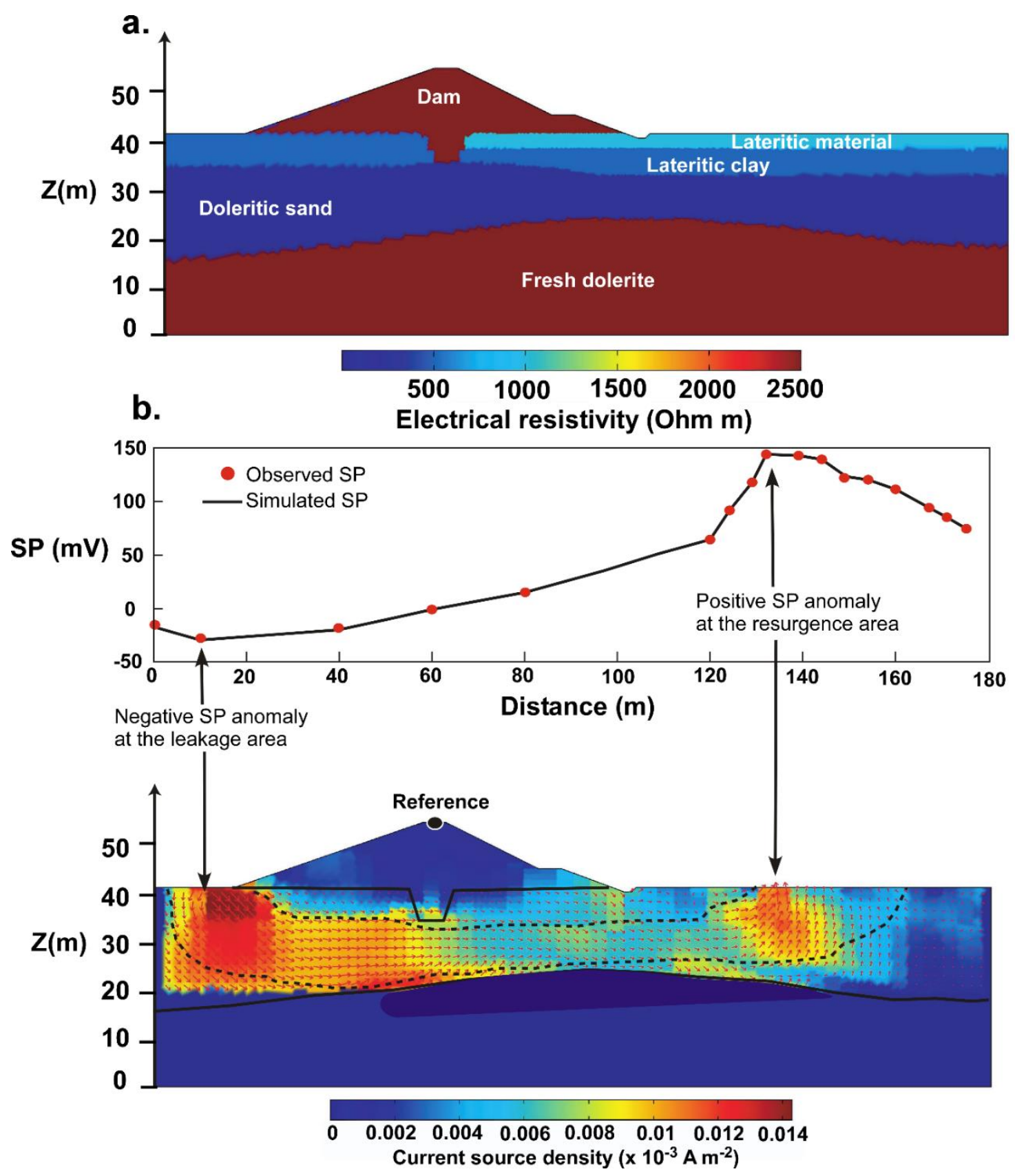

892 Figure 15. Field study 3: Resistivity model and self-potential measurements. a. The resistivities

893 of each of the components are estimated from ERT. This resistivity model is used in the forward 894 problem to generate the simulated self-potential response. b. The observed self-potential signal 895 shows a negative anomaly upstream and a positive one downstream. The estimated current 896 density is higher at leakage and resurgence areas and it exhibits a continuous pattern which is 897 indicative of the seepage flow path.

898 


\section{Field study 3}

a.

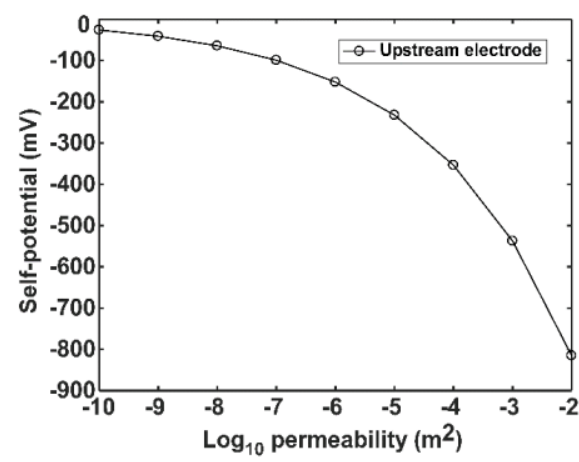

b.

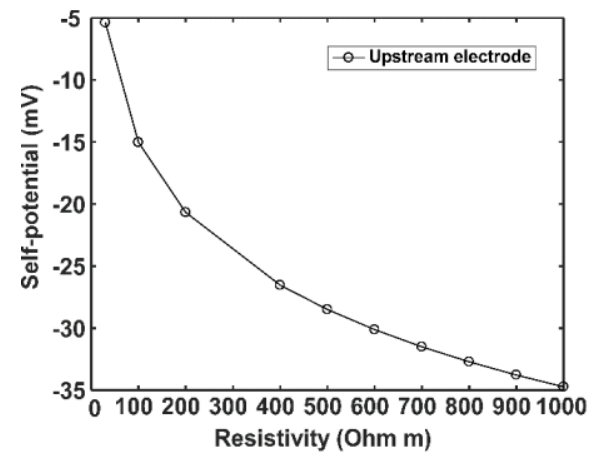

C.

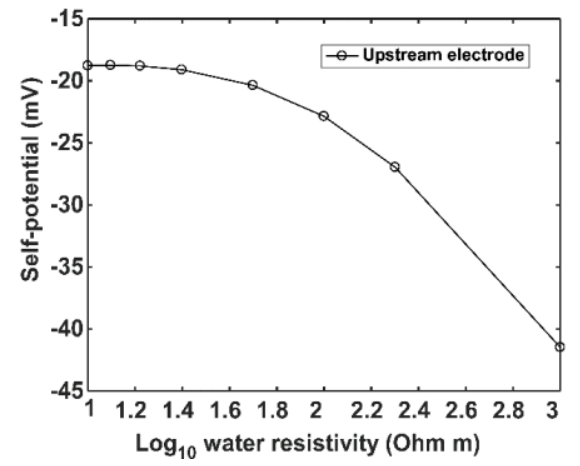

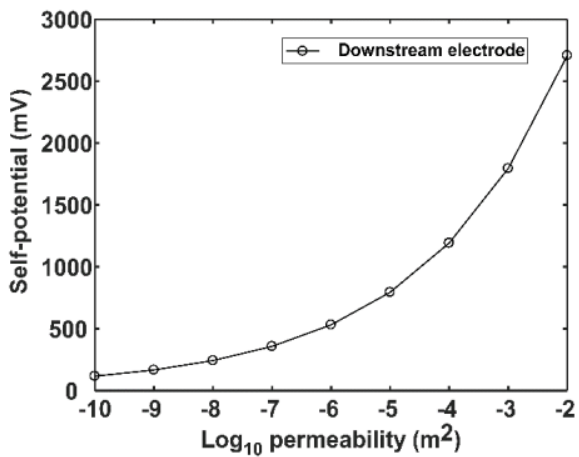
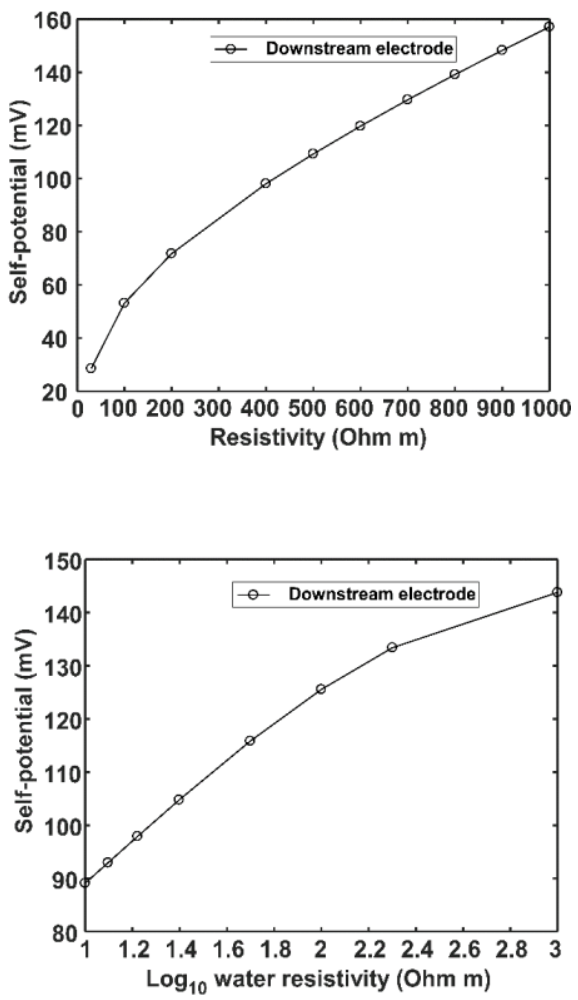

Figure 16. Field study 3: Sensitivity analysis on some of the components of the studied dam. a. Sensitivity analysis on the permeability of the seepage flow path properties. The self902 potential anomalies are retrieved with a permeability of the seepage flow path that is ranging 903 between $10^{-10} \mathrm{~m}^{2}$ and $10^{-9} \mathrm{~m}^{2} \mathbf{b}$. Sensitivity analysis on the resistivity of the seepage flow path. 904 A resistivity comprised between $600 \mathrm{Ohm} \mathrm{m}$ and $900 \mathrm{Ohm}$ m reproduces the observed self905 potential anomalies of -10 to $-15 \mathrm{mV}$ upstream and $150 \mathrm{mV}$ downstream. This resistivity range 906 is in accordance with the order of magnitude observed on the resistivity tomograms. c. 907 Sensitivity analysis on the resistivity of the water in the dam reservoir. The resistivity of the 908 pore water is varied within a wide range of resistivities as shown in the figure. The downstream 909 and upstream self-potential anomalies are well reproduced with a resistivity whose logarithm 910 is ranging from 2.4 to 3. 
a.

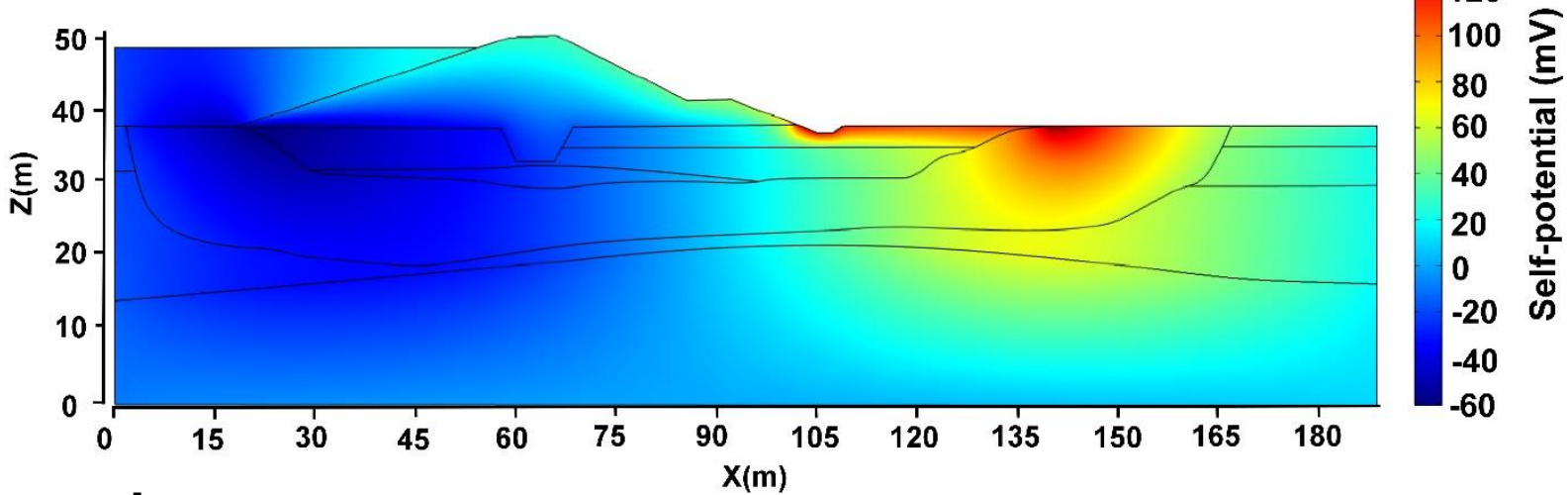

b.

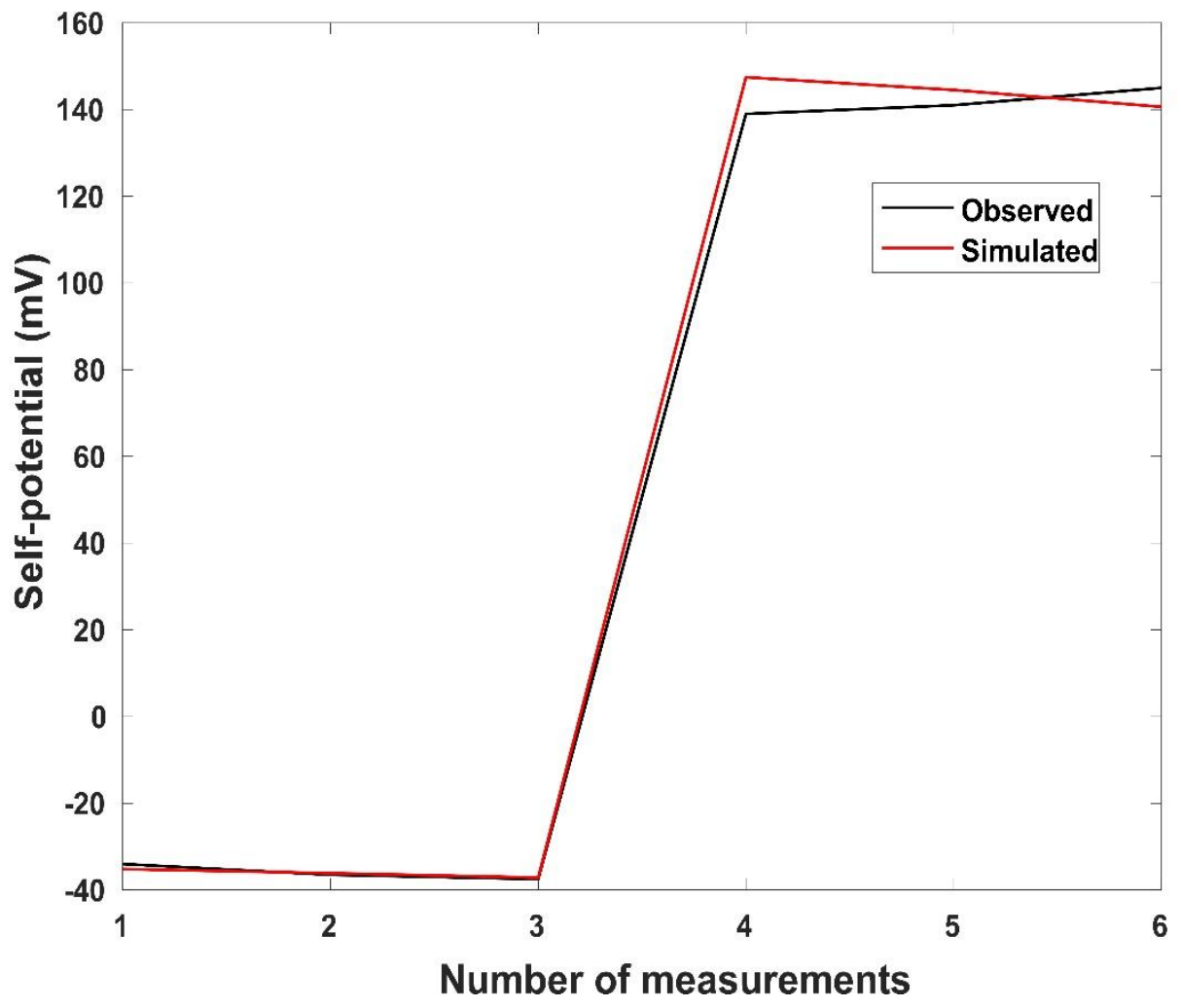

912

Number of measurements

913

914 Figure 17. Case study 2: self-potential signal: a. Simulated self-potential distribution. b.

915 Observed against simulated self-potential signal. There is a very good match between the 916 observed and self-potential signal. The self-potential distribution clearly shows regions of 917 negative and positive self-potential anomalies at the ends of the preferential flow path. 